School Participation in Rural India*

By

Jean Drèze

Centre for Development Economics (Delhi School of Economics)

$\&$

Geeta Gandhi Kingdon

Institute for Economics and Statistics (University of Oxford)

This Draft: August 1999

DEDPS No. 18

August 1999
The Development Economics Discussion Paper Series

The Suntory Centre

The Suntory and Toyota International Centres for Economics and Related Disciplines

London School of Economics

Houghton Street

LONDON WC2A $2 \mathrm{AE}$

Tel: 01719556698

\footnotetext{
* We are grateful to Angus Deaton for valuable suggestions and comments, and to Anuradha De for helping us to master the data set. Jean Drèze's work builds on his involvement with the Network on Inequality and Poverty in Broader Perspective, based at Princeton University. Geeta Gandhi Kingdon's work was supported by the Nuffield Foundation and the Wellcome Trust.
} 
School Participation in Rural India

By

Jean Drèze

Centre for Development Economics (Delhi School of Economics)

$\&$

Geeta Gandhi Kingdon

Institute for Economics and Statistics (University of Oxford)

This Draft: August 1999

\begin{abstract}
This paper presents and analysis of the determinants of school participation in rural north India, based on a recent household survey which includes detailed information on school characteristics. School participation, especially among girls, responds to a wide range of variables, including parental education and motivation, social background, dependency ratios, work opportunities, village development, teacher postings, teacher regularity and midday meals. The remarkable lead achieved by the state of Himachal Pradesh is fully accounted for by these variables. School quality matters, but it is not related in a simple way to specific inputs.
\end{abstract}

Keywords: Education; India;child labour; school quality

JEL classification: H52, I2, J13, O15

(C) by Jean Drèze and Geeta Gandhi Kingdon. All rights reserved. 


\title{
SCHOOL PARTICIPATION IN RURAL INDIA
}

\author{
Jean Drèze and Geeta Gandhi Kingdon*
}

August 1999

\begin{abstract}
This paper presents an analysis of the determinants of school participation in rural north India, based on a recent household survey which includes detailed information on school characteristics. School participation, especially among girls, responds to a wide range of variables, including parental education and motivation, social background, dependency ratios, work opportunities, village development, teacher postings, teacher regularity and mid-day meals. The remarkable lead achieved by the state of Himachal Pradesh is fully accounted for by these variables. School quality matters, but it is not related in a simple way to specific inputs.
\end{abstract}

1. Introduction

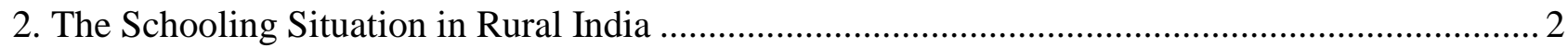

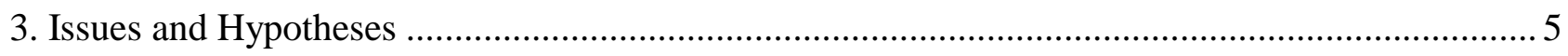

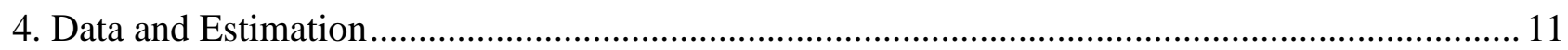

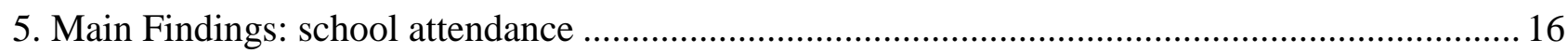

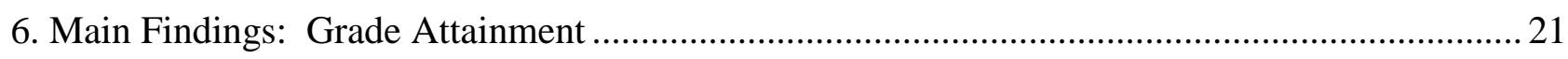

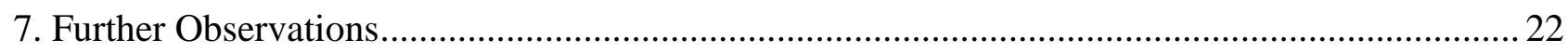

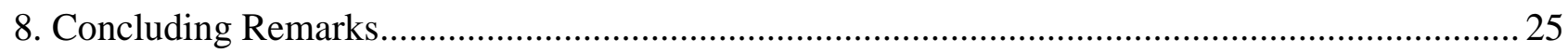

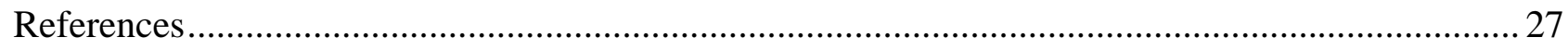

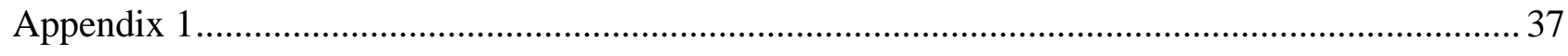

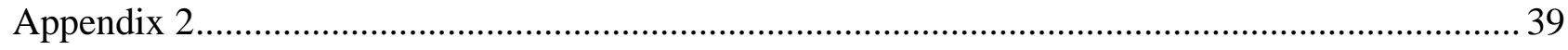

* Centre for Development Economics (Delhi School of Economics) and Institute of Economics and Statistics (University of Oxford), respectively. We are grateful to Angus Deaton for valuable suggestions and comments, and to Anuradha De for helping us to master the data set. Jean Drèze's work builds on his involvement with the Network on Inequality and Poverty in Broader Perspective, based at Princeton University. Geeta Gandhi Kingdon's work was supported by the Nuffield Foundation and the Wellcome Trust. 


\title{
SCHOOL PARTICIPATION IN RURAL INDIA
}

\author{
Jean Drèze and Geeta Gandhi Kingdon
}

\section{Introduction}

About one third of all Indian children are out of school. In the large north Indian states, which account for over 40 per cent of the country's population, the proportion of out-of-school children in the 6-14 age group is as high as 41 per cent, rising to 54 per cent among female children. ${ }^{1}$ Considering the crucial role of elementary education in development, the universalization of schooling in India is one of the most urgent development issues in the world today.

Yet, relatively little is known about the reasons why so many Indian children are out of school. In public debates, the tendency is to highlight a single 'explanation'. In official circles, for instance, the problem is often blamed on parental indifference towards education -- a convenient argument since it diverts attention from the responsibility of the state. Others consider that child labour is the overwhelming obstacle: according to the Campaign Against Child Labour (1997), India has more than 60 million child labourers, working 12 hours a day on average. Neither of these single-focus explanations, however, stands up to careful scrutiny (Bhatty et al., 1997). This is not to deny that they contain a grain of truth. The real challenge is to build a balanced picture of the determinants of school participation, which integrates different lines of explanations: lack of parental or child motivation, the costs of schooling, the demands of child labour, and the low quality of schooling, among others.

As a modest step in that direction, this paper presents an analysis of the determinants of school participation based on a recent survey of schooling in north India, the PROBE survey. ${ }^{2}$ This is not the first study of its kind; earlier analyses of a similar inspiration include Duraisamy and Duraisamy (1991), Duraisamy (1992), Kingdon (1994, 1996, 1998), Labenne (1995, 1997), Jayachandran (1997), and Sipahimalani (1998), among others. The PROBE survey, however, offers unique possibilities for scrutinising different influences on schooling decisions, in so far as it contains detailed information not only on the characteristics of about 4,400 children and their

\footnotetext{
${ }^{1}$ Calculated from International Institute for Population Sciences (1995), p.56. The reference year is 1992-93.
}

${ }^{2}$ The acronym PROBE refers to the Public Report on Basic Education where the main findings of the survey were presented (The PROBE Team, 1999). Both of us were personally involved in the survey, in collaboration with other researchers. In that sense, this study may be considered as an exercise in 'participatory econometrics' (Rao, 1998). 
households, but also on the schools to which these children have access. In particular, this survey enables us to examine the influence of different types of 'school quality' variables on school participation and educational achievements in rural India.

The outline of the paper is as follows. The next section introduces the reader to the schooling situation in rural India. Section 3 outlines the main issues and hypotheses selected for investigation. In section 4, we briefly discuss the data set and some estimation issues. The main results are presented in sections 5 and 6 , followed by some variants and extensions of the baseline regressions in section 7 . The last section summarises the main findings.

\section{The Schooling Situation in Rural India}

By way of orientation, we begin with a brief sketch of the schooling situation in rural India, with specific reference to the four major states covered by the PROBE survey: Bihar, Madhya Pradesh, Rajasthan, Uttar Pradesh (hereafter the 'PROBE states'). The main features of the schooling situation in these states, as they emerge from the PROBE survey, include the following (see also Table 1$)^{3}$

School availability: Most villages have at least one government primary school (classes 1 to 5). Government schools charge negligible fees, and never refuse to enrol a child. There are no Board examinations until class 5 (in fact, well after class 5 in most states), but primary schools conduct school tests and children are sometimes asked to repeat a particular class. Only a minority of villages -- about 20 per cent -- have a 'middle' school (classes 6 to 8), but 55 per cent of the rural population live within 2 kilometres of a middle school.

Private schools: In addition to government schools, private schools with primary sections are available in a significant minority (about 17 per cent) of villages. Private schools charge fees, and generally attract children from relatively privileged families, though children from poor families are not entirely excluded.

Parental motivation: Qualitative data from the PROBE survey suggest that parental interest in education is generally quite high. Most parents would like their children (particularly sons) to be educated, and favour compulsory education for all children. However, they have a dim view of the schooling system. Low teaching standards is their main complaint.

\footnotetext{
${ }^{3}$ This sketch is based on the findings reported in The PROBE Team (1999); it is consistent with other field studies as well as with secondary data. For a useful survey of field-based investigations of schooling in India, see Bhatty (1998). Important sources of secondary data include annual reports of the Department of Education, the Sixth All-India Educational Survey (National Council of Educational Research and Training, 1997), National Sample Survey Organisation (1997), National Council of Applied Economic Research (1996a, 1996b), and the decennial censuses.
} 
School participation: In the 6-14 age group, according to the PROBE survey, 85 per cent of boys and 56 per cent of girls are currently enrolled in school. Among ever-enrolled children in the 13-18 age group, 81 per cent have completed class 5 .

Child labour: Time utilisation data from the PROBE survey indicate that out-of-school children work about 4.7 hours a day on average (about 2 hours more than school-going children), mainly helping their parents at home and in the fields. Work hours are a little longer for girls than for boys, and particularly long for eldest daughters in poor families, many of whom are expected to take care of younger siblings.

School quality: Aside from parental testimonies, the PROBE survey found much direct evidence of the dismal state of government schools. To illustrate: (1) Only one fourth of the sample schools have at least two teachers, two all-weather classrooms, and some teaching aids; (2) If all children aged 6-10 in the sample villages were enrolled in a government primary school, there would be about 113 pupils per classroom on average, and 68 pupils for each teacher; (3) At the time of the investigators' visit, one third of the headmasters were absent, one third of the schools had a single teacher present, and about half of the schools had no teaching activity; (4) In many schools, class-1 pupils are systematically neglected. In these and other respects, there is a great deal of variation in the quality of schooling between different schools and communities.

Silver lining: Aside from the four major states listed earlier, the PROBE survey also covered Himachal Pradesh, a smaller state located in the Himalayan region. In sharp contrast with the other states, Himachal Pradesh had high rates of school participation (96 per cent of all children aged 6-14 were studying), and low educational disparities between boys and girls as well as between different communities. ${ }^{4}$ There were also many signs of a higher quality of schooling in Himachal Pradesh, e.g. lower pupil-teacher ratios, better teaching standards, and a more cooperative rapport between parents and teachers. This success is all the more impressive considering that, not so long ago, Himachal Pradesh was widely regarded as a 'backward' region of north India.

${ }^{4}$ These findings are consistent with secondary data. According to the National Family Health Survey 1992-3, for instance, only one major state (Kerala) has higher rates of school attendance than Himachal Pradesh (International Institute for Population Sciences, 1995, p.56). 
Table 1

Basic statistics on sample villages and households

\section{PROBE states}

Himachal Pradesh

(Bihar, Madhya Pradesh, Rajasthan,

Uttar Pradesh)

Number of sample villages

Number of sample households

1221

154

girls

boys

girls

boys

Number of children 6-14 in sample households

$1362 *$

1558

166

163

Proportion of children 6-14 in sample households:

Enrolled in a school

$56.2^{*}$

85.4

94.6

97.5

Not enrolled

$43.8^{*}$

14.6

5.4

Total

100.0

100.0

100.0

100.0

government

private government

private

Number of sample schools

195

41

48

Proportion of sample schools that are:

Primary

83.1

61.0

93.7

Middle with a primary section

16.4

29.3

2.1

Secondary with a primary section

0.5

9.7

4.2

Total

100.0

100.0

100.0

100.0

female

161

85.1

14.9

100.0 male

675

76.0

24.0

100.0 female

90

75.6

Private schools

Total

100.0

100.0

* These figures involve ad hoc corrections for under-enumeration of adolescent girls; our own analysis does not include such corrections.

Source: The PROBE Team (1999, p.7). The information given in this table pertains to the full set of 188 villages covered by the PROBE survey. The analysis reported in this paper, however, is based on a sub-set of 122 villages where household data were collected (see Appendix 1 for details). 


\section{Issues and Hypotheses}

\section{$\underline{\text { School participation as a household decision }}$}

The main focus of this paper is on school participation as a household decision. ${ }^{5}$ At a general level, this decision may be thought to depend on the costs and benefits of education. The costs, in turn, depend both on the opportunity cost of a child's time, and on the direct costs of schooling (e.g. expenditure on fees, books and stationery). The benefits include tangible economic returns, mainly in the form of improved earning opportunities as well as more productive work within the household. ${ }^{6}$ Other possible benefits of elementary education include better health, higher self-esteem, improved social status, greater bargaining power, and the joy of learning, among others.

This cost-benefit view of schooling decisions has to be qualified in several respects. First, it is important to take a considered view of the relevant costs and benefits of schooling. The benefits derive not only from schooling attainments per se (e.g. having a school certificate may help to get a job), but also from cognitive and other skills which the schooling system is supposed to impart (e.g. literacy, numeracy and knowledge). ${ }^{7}$ This is one major reason why school participation is likely to be sensitive to the quality of schooling. On the cost side, it should be remembered that the costs of schooling are not confined to cash expenditure and foregone earnings. Sending children to school on a regular basis also requires a great deal of parental effort in terms of, say, motivating them to study, preparing them to go to school in the morning, and helping them with homework.

Second, the cost-benefit view assumes that schooling decisions are made by parents (children are unlikely to be motivated by cost-benefit calculations). In practice, school participation is effectively a joint decision of parents and children, whose interests may not coincide. The PROBE survey suggests that, if a child is unwilling to go to school, it is often difficult for the parents to overcome her reluctance (just as it is hard for a child to attend school against his parents' wishes). The fact that school participation is contingent on the motivation of the child is another reason why various aspects of 'school quality' (e.g. the facilities available, and whether games are played in the classroom) are likely to matter.

Third, there is a specific asymmetry of interests between parents and children when it comes

5 A child is taken to 'participate' in the schooling system if she is reported by her parents to be enrolled in a school. The terms 'school participation' and 'school attendance' will be used interchangeably.

${ }^{6}$ On economic returns to education in India, see Kingdon and Unni (1998), and the literature cited there.

7 There is evidence suggesting that much of the economic return to education accrues to cognitive skills acquired through schooling rather than to formal school qualifications (Boissiere, Knight, and Sabot, 1985) - negating the screening or credentialist hypotheses. An additional benefit of skills acquired in elementary education is that they make it easier to continue studying beyond that level. 
to the education of girls. In north India, most daughters leave their parents at the time of marriage and join their husband's family, usually in a different village. After marriage, a daughter's relations with her parents are quite distant (usually confined to occasional visits). In the light of this practice, parents often consider that they have no direct stake in the education of a daughter. One qualification is that educating a daughter may facilitate her marriage, and/or reduce its costs. ${ }^{8}$ Also, parents may send a daughter to school out of genuine concern for her own well-being, even if they have little to gain from it themselves. Generally, schooling decisions are likely to depend not only on the perceived interests of individual household members, but also on how differences of interest are resolved within the family.

Fourth, the perceived costs and benefits of education reflect the information available to parents. For instance, in communities with low levels of education, illiterate parents often have a limited perception of the benefits of education. ${ }^{9}$ And most rural parents find it quite difficult to figure out what goes on in the classroom, whether their children are making good progress, and how much they will benefit from what they learn.

Fifth, the subjective valuation of costs and benefits should not be considered as 'exogenous'. For instance, the willingness of parents to send their own children to school may depend on whether other parents in their community do so. Similarly, a child's inclination to go to school is likely to depend on school attendance patterns in his or her peer group. Public initiatives such as compulsory education and awareness campaigns also affect social norms about schooling matters.

\section{A simple model}

Following a well-established tradition in economics, we suspend these qualifications for the time being and proceed with a simple model of schooling decisions in the cost-benefit framework.

If all households face the same prices for various educational inputs (fees, books, etc.), then expenditure on the education of a particular child (say $\mathrm{x}$ ) may be treated as a 'composite commodity'. ${ }^{10}$ A household is assumed to choose $\mathrm{x}$ so as to maximise

$$
\mathrm{B}(\mathrm{x} ; \mathbf{w}, \mathbf{z})+\mathrm{U}(\mathrm{Y}-\mathrm{c}-\mathrm{x} ; \mathbf{w})
$$

\footnotetext{
${ }^{8}$ For further discussion of this point, see The PROBE Team (1999), chapter 3.

${ }^{9}$ Asked whether it was important for a girl to receive education, one mother interviewed in the PROBE survey replied, 'How do I know? I have never seen an educated woman'.

${ }^{10}$ This model focuses on a single child. Sibling effects are not investigated in this paper, due to data limitations (which we hope to overcome in future work).
} 
where $\mathbf{w} \equiv\left\{\mathrm{w}_{\mathrm{h}}\right\}$ is a vector of household characteristics, $\mathbf{z} \equiv\left\{\mathrm{z}_{\mathrm{k}}\right\}$ is a vector of school characteristics, $\mathrm{Y}$ is income, c represents the fixed costs of schooling (e.g. opportunity cost of child's time), $\mathrm{U}$ is utility from current consumption and $\mathrm{B}$ represents the perceived benefits of education. We are assuming here that the household's objective function is 'separable' (without loss of generality, additively separable) with respect to consumption and schooling. The functions $\mathrm{U}($.$) and \mathrm{B}($.) are household-invariant, but $\mathrm{c}, \mathrm{x}, \mathrm{Y}, \mathbf{w}$ and $\mathbf{z}$ are household-specific (though superscripts denoting households are omitted, for clarity). $\mathrm{B}($.$) and \mathrm{U}($.$) are assumed to be$ increasing and concave in $\mathrm{x}$ and $\mathrm{Y}$, respectively. $\mathrm{B}($.) is also assumed to be increasing in $\mathbf{z}$, the components of which may be thought of as indicators of 'school quality'.

If the household decides not to enrol the child in the first place, then (1) reduces to

$\mathrm{U}(\mathrm{Y} ; \mathbf{w})$.

Let $x^{*}(Y, \mathbf{w}, \mathbf{z})$ be the solution of the above maximisation problem, and $\mathrm{V}(\mathrm{Y}, \mathbf{w}, \mathbf{z})$ the maximum value function. ${ }^{11}$ Then the natural criterion for enrolling the child is:

Enrol if $\mathrm{V}(\mathrm{Y}, \mathbf{w}, \mathbf{z})-\mathrm{U}(\mathrm{Y} ; \mathbf{w})>0$.

Further, when a child is enrolled, the first-order condition for maximising (1) is:

$\mathrm{B}_{\mathrm{X}}=\mathrm{U}_{\mathrm{Y}}$

where subscripts (here and elsewhere) denote partial derivatives.

This simple model leads to several predictions. To start with, it implies that enrolment is non-decreasing with respect to school quality. This follows from differentiating $\mathrm{V}$ with respect to $\mathrm{z}_{\mathrm{k}}$ and applying the envelope theorem:

$\partial \mathrm{V} / \partial \mathrm{z}_{k} \equiv \mathrm{B}_{k}>0$

where $B_{k}$ denotes the partial derivative of $B$ with respect to $z_{k}$. Combining this with (3), it is clear that an improvement in school quality either has no effect on enrolment, or induces the household to enrol the child (if the improvement raises $z_{k}$ beyond the 'threshold' value where (3) is satisfied).

This result applies to initial enrolment, and it may be thought that a similar result would apply to education expenditure (one form of which is continuation of school participation over the

${ }^{11}$ We assume that $\mathrm{x}^{*}$ is always strictly positive, i.e., conditional on a child being enrolled, it is always optimal to spend at least some money on his or her education (in addition to the fixed costs). A sufficient condition for this is that $\mathrm{B}_{\mathrm{x}}$ tends to infinity as $\mathrm{x}$ tends towards zero. 
years). This, however, is not quite the case. To see this, consider the effect of a small change $\mathrm{dz}_{\mathrm{k}}$ on $x^{*}$. Differentiating (4), we obtain:

$$
\partial \mathrm{x}^{*} / \partial \mathrm{z}_{\mathrm{k}} \equiv-\mathrm{B}_{\mathrm{xk}} /\left(\mathrm{B}_{\mathrm{xx}}+\mathrm{U}_{\mathrm{YY}}\right)
$$

with obvious notation for the second derivatives. Since the denominator is negative, (6) shows that an improvement in school quality raises private expenditure on education if and only if the two are complementary inputs in the benefit function B. That this need not be the case can be illustrated with a simple example. Suppose that parents are keen to have literate children, but attach little importance to education beyond literacy. In that case, an improvement in school quality that accelerates the pace of learning would lead them to withdraw their children earlier. In general, however, it is plausible to think that private expenditure and school quality are complements rather than substitutes.

Next, we consider income effects. Applying the envelope theorem again, the derivative of the left-hand side of the inequality in (3) with respect to $\mathrm{Y}$ is

$$
\mathrm{U}_{\mathrm{Y}}(\mathrm{Y}-\mathrm{c}-\mathrm{X} ; \mathbf{w})-\mathrm{U}_{\mathrm{Y}}(\mathrm{Y} ; \mathbf{w})
$$

Since U(.) is concave, this expression is positive. Hence, much as with school quality, enrolment is non-decreasing with respect to income. This makes sense, since (in this model) a higher income essentially makes education more affordable, nothing more. ${ }^{12}$ Differentiating (4) with respect to $\mathrm{Y}$ we obtain a similar result for education expenditure:

$$
\partial \mathrm{x}^{*} / \partial \mathrm{Y} \equiv \mathrm{U}_{\mathrm{YY}} /\left(\mathrm{B}_{\mathrm{XX}}+\mathrm{U}_{\mathrm{YY}}\right)
$$

The right-hand side, as expected, is positive. A similar derivation shows that enrolment and education expenditure are non-increasing and decreasing (respectively) with respect to c, the fixed costs of schooling.

Finally, turning to household characteristics, the derivative of $\mathrm{x}^{*}$ with respect to $\mathrm{w}_{\mathrm{h}}$ may be written as:

$$
\partial \mathrm{x}^{*} / \partial \mathrm{w}_{\mathrm{h}} \equiv\left(\mathrm{U}_{\mathrm{Yh}}-\mathrm{B}_{\mathrm{xh}}\right) /\left(\mathrm{B}_{\mathrm{xx}}+\mathrm{U}_{\mathrm{YY}}\right)
$$

Consider, then, a household characteristic which enhances the (perceived) marginal returns to schooling $\left(\mathrm{B}_{\mathrm{xh}}>0\right)$. Possible examples of such characteristics are membership of a well-connected

${ }^{12}$ In some neo-classical models of human capital, investment in education is independent of initial wealth if there are perfect credit markets. There is much evidence, however, that credit markets in rural India are far from perfect (see Drèze, Lanjouw, and Sharma, 1997, and the literature cited there). 
kinship group and a personal inclination for learning. Equation (9) tells us that households with such characteristics are likely to invest more in education, unless the same characteristics also raise the marginal utility of income by a sufficient amount. In many cases, there will be no particular reason to expect the latter to happen.

\section{$\underline{\text { Specific issues }}$}

This simple model provides one convenient framework for interpreting the regression results, though we shall occasionally deviate from it to accommodate the reservations discussed earlier. Some specific household characteristics and school characteristics are of particular interest.

Caste: It is well known that school participation and educational levels in India are particularly low among socially disadvantaged communities, notably the 'scheduled castes'. However, several aspects of the caste bias require further exploration. First, it is not clear whether (and to what extent) the caste bias remains after controlling for household income, parental literacy and related characteristics. ${ }^{13}$ Second, it is conceivable that positive-discrimination policies (e.g. school incentives for scheduled-caste pupils and caste-based employment reservation) have succeeded in eliminating the caste bias in recent years. Hence, an update based on 1996 data would be useful. Third, one earlier study based on 1995 data (Kingdon, 1998) finds that, conditional on school enrolment, the achievements of scheduled-caste pupils (measured by years of education attained) are no lower than those of other pupils. This finding can be interpreted as tentative evidence that discrimination within the schooling system is not the root of the problem. ${ }^{14}$ The PROBE survey is an opportunity to re-examine this pattern.

Parental education: Parental education has often emerged as a powerful predictor of school attendance among children. This pattern is usually read as a causal link running from parental education to school attendance, but it may also reflect the influence on both of these of some variable not included in the model (e.g. the quality of schooling facilities in the area). Whether parental education continues to act as a strong determinant of school attendance even after introducing extensive controls for other household and school characteristics is an open question. Another interesting issue concerns the respective influences of paternal and maternal education on male and female schooling. One earlier study (Usha Jayachandran, 1997) suggests that intergenerational same-sex effects are stronger than the cross-sex effects, i.e. boys' schooling is more responsive to father's education than to mother's and vice-versa for girls. But again, these intergenerational correlations may reflect the influence of missing variables and call for further scrutiny.

${ }^{13}$ Some earlier studies suggest that the educational disadvantage of the scheduled castes persists even after controlling for household income and parental literacy; see Jayachandran (1997), Labenne (1997), Drèze and Sharma (1998). The PROBE survey allows us to control for a wider range of relevant household variables.

\footnotetext{
${ }^{14}$ Kingdon's (1998) estimation procedure corrected for possible 'selection bias'.
} 
Land ownership: The effect of land ownership on school participation is hard to predict. On the one hand, land is a form of wealth, and wealth is likely to have a positive effect on school attendance. On the other hand, land ownership raises the productivity of child labour within the household, and hence the opportunity cost of school attendance. The net effect is an empirical issue. Similar remarks apply to the ownership of farm animals (cows, goats, etc.).

Pupil-Teacher ratios: The relation between pupil-teacher ratios (or 'class size') and pupil achievements (typically measured by test scores) is a controversial subject. Early studies for developed countries, reviewed in Hanushek (1986), suggest that pupil achievements are independent of the pupil-teacher ratio, after controlling for pupil characteristics. In developing countries, too, evidence of a negative effect of class size on pupil achievements has proved elusive (see Fuller, 1986, and Hanushek, 1995, for international evidence; and Kingdon, 1996, for India). However, some of the studies cited in this context are likely to suffer from a simultaneity bias, as better schools or teachers attract more pupils. Further research on this subject has focused on identifying credible instruments for class size, and at least some recent studies have found a significant negative relationship between class size and pupil achievements. ${ }^{15}$ However, the jury is still out. In India specifically, it would surprising if pupil-teacher ratios did not matter. Indeed, overcrowding is commonly mentioned by teachers as one of their major problems, and qualitative observations from the PROBE survey lend much credibility to this concern (The PROBE Team, 1999). So far, however, this issue has not been the object of detailed investigation. ${ }^{16}$

School quality: Aside from the teacher-pupil ratio, commonly-used indicators of school quality include teacher salaries, teacher experience or training, expenditure per pupil, and various indicators of physical infrastructure. ${ }^{17}$ In the Indian context, however, there is a case for focusing on a different list of school-quality variables. For instance, teacher salaries are unlikely to matter, since salaries bear little relation to qualifications or performance. ${ }^{18}$ Similarly, expenditure per pupil has little relevance in this case, since it is essentially the product of teacher salaries (which account for about 95 per cent of recurrent expenditure) and the pupil-teacher ratio. On the other hand, the qualitative findings of the PROBE survey clearly point to the need to capture other aspects of school quality such as teaching standards, classroom activity and incentive schemes. One goal of this study is to examine the respective influences of different aspects of school quality on school participation. The following indicators were considered, among others: pupil-teacher ratios; physical facilities; the

${ }^{15}$ See e.g. Angrist and Lavy (1996), Case and Deaton (1997).

16 For earlier analyses of the relation between teacher-pupil ratios and school participation (or pupil achievements) in India, see Heyneman and Loxley (1982, 1983) and Kingdon (1994, 1996).

${ }^{17}$ See the reviews by Fuller (1986) and Hanushek $(1986,1995)$.

${ }^{18}$ In an analysis of survey data for Lucknow city, Kingdon (1996) finds no relation between teacher salaries and pupil achievements after controlling for teacher education and training as well as for pupil, parental and school characteristics (on this, see also Fuller, 1986). 
presence of female teachers; teacher attendance rates; frequency of inspection; the provision of school meals and other pupil incentives; teacher qualifications; teacher training; the frequency and severity of physical punishment; classroom activity levels; and indicators of teacher-parent cooperation.

\section{Data and Estimation}

The data set

The PROBE survey collected household data in 122 randomly-selected villages of Bihar, Madhya Pradesh, Rajasthan, Uttar Pradesh and Himachal Pradesh. These five north Indian states account for about 40 per cent of India's population, and a little over half of all out-of-school children. In each village, all school facilities were surveyed and a random sample of 12 households were interviewed. Further details of the sampling procedure and related matters are given in Appendix 1.

The analysis draws on three components of the PROBE survey: the Village Questionnaire, the School Questionnaire and the Household Questionnaire. The primary objective is to identify the determinants of school attendance and educational attainment. Specifically, we focus on the following dependent variables (in each case, individual children are the basic units of observation): ${ }^{19}$

(1) Initial enrolment: This is a dummy variable taking value 1 if the child has ever been enrolled in a school, and 0 otherwise.

(2) Current enrolment: A dummy variable taking value 1 if the child is currently enrolled, and 0 otherwise.

(3) Grade Attainment: This is the highest grade achieved by the child.

Our interest is in primary schooling (the main focus of the PROBE survey itself). Accordingly, when 'current enrolment' is used as the left-hand side variable, the observations are restricted to children in the 5-12 age group. ${ }^{20}$ When 'grade attainment' is the dependent variable,

${ }^{19}$ In principle, a fourth dependent variable could have been considered: 'grade-for-age', i.e. the grade in which a child of a given age is studying (as in Case and Deaton, 1997). This is essentially an indicator of the efficiency of the system in promoting pupils. However, grade-for-age is a dubious indicator in this context, because (1) some states have a policy of 'automatic promotion' of children at the primary level, (2) children are often enrolled in class 1 at an early age, for reasons that have nothing to do with school quality, and (3) age data are unlikely to be very precise.

${ }^{20}$ In the states concerned, the primary stage consists of grades 1-5. This roughly corresponds to the 6-10 age group, though some children are enrolled in grade 1 at age 5 (and, in a few cases, even earlier), and many are still in primary school at the age of 11 or even 12 . 
the reference group consists of children aged 13-18 (i.e. children who are supposed to have completed primary schooling). For 'initial enrolment', children aged 5-18 are taken as the reference group.

The right-hand side variables consist of individual characteristics, household characteristics, school characteristics and village characteristics. They are listed in Table 2a, together with their sample means. ${ }^{21}$ Precise definitions, and some explanatory notes, are given in Table $2 \mathrm{~b}$. We proceed with further comments on specific variables.

\section{$\underline{\text { Teacher inputs }}$}

As discussed earlier, the relation between pupil-teacher ratios and pupil achievements has received sustained attention in the literature. Earlier studies typically have test scores (or some related measure of pupil achievements) on the left-hand side, and the pupil-teacher ratio (or some instrument for it) on the right-hand side. In the present case, however, the left-hand side variable is an indicator of school participation such as 'initial enrolment'. This makes it inappropriate to put the pupil-teacher ratio on the right-hand side, since the latter is affected by enrolment rates. When an extra child is enrolled, the pupil-teacher ratio increases, and this positive feedback makes it hard to capture any negative effect which the pupil-teacher ratio might otherwise have on enrolment rates. ${ }^{22}$ Nor is it easy to find credible instruments for the pupil-teacher ratio.

To get around this endogeneity problem, at least partly, we use the child-teacher ratio (CTRATIO) in the village (i.e. the total number of children divided by the total number of teachers at the primary level) as an alternative indicator of teacher inputs. ${ }^{23}$ There are two ways of thinking about the relevance of this indicator. First, it can interpreted as a useful correlate of the pupilteacher ratio. Second, it can be thought of as a useful indicator of teacher inputs in its own right. The PROBE survey suggests, for instance, that school participation is influenced by 'enrolment drives' undertaken by teachers at the beginning of the year; the effectiveness of these enrolment drives is likely to be sensitive to the child-teacher ratio in the village. In this paper, we follow the second interpretation - an attempt to pursue the first interpretation is in progress.

This is not the end of the endogeneity problem, however, since the number of teachers

${ }^{21}$ There are differences between the sample means reported in Table 2 and the corresponding data reported in The Probe Team (1999). This is because the age ranges for which means are calculated differ, and also because our sample discards observations for which the relevant data were not available.

${ }^{22}$ The full feedback effect actually follows a seesaw pattern: as more children are enrolled, the pupil-teacher ratio increases, then falls abruptly if and when an extra teacher is appointed, then rises again, etc.

${ }^{23}$ The number of children in each village was estimated as a constant proportion of the total village population. The constant is the share of the relevant age group in the total population of the PROBE states, according to 1991 census data. 
posted in a village may be sensitive to school participation rates. Indeed, teacher postings are supposed to be geared partly to an official norm of 40:1 for the pupil-teacher ratio. If this rule is observed, then an increase in school participation in a certain range (e.g. raising the number of pupils from 35 to 45 ) could lead to a decline in the child-teacher ratio (as extra teachers are appointed), leading to a spurious impression that lower child-teacher ratios are 'causing' higher school participation rates.

The official norm, however, is routinely violated. For one thing, it is undermined by an overall shortage of teachers. Further, teachers tend to lobby for convenient postings (e.g. in villages with better facilities and connections), and their pressures are quite effective, leading to a highly uneven distribution of teachers across villages. In the extreme case where teacher postings are entirely determined by exogenous village characteristics, the endogeneity problem disappears. ${ }^{24}$

Another consideration reduces the endogeneity problem: the 40:1 norm, when it is applied at all, is based on school enrolment data, which are known to be fudged. The different ways in which fudging takes place are discussed in the PROBE report (The PROBE Team, 1999, pp.91-92). For present purposes, it is sufficient to note that, in many cases, the number of children listed in the school register(s) is probably closer to the total number of children in the village than to the actual number of children attending school. To sum up, it is reasonable to assume that teacher postings are driven primarily by exogenous village characteristics, including the number of children in the village, and only marginally by school participation rates. If so, the endogeneity problem need not be serious.

For the time being, then, we treat the child-teacher ratio as an exogenous indicator of teacher inputs. In section 7, however, we shall experiment with alternative treatments of this variable. As will be shown there, the coefficients of the other variables vary little between different specifications. Hence the endogeneity problem, such as it may be, does not undermine the findings related to those variables. It mainly affects the credibility and interpretation of the coefficient of CTRATIO.

$\underline{\text { School quality indicators }}$

As shown in Table 2, the regressions include eight indicators of school quality (other than the child-teacher ratio): whether the school provides a mid-day meal (GIVEMEAL); an index of infrastructure (INFRA); whether the school was open for 6 days during the 7 days preceding the survey (DAYS6); whether the class-1 teacher lives in the village (TLIVEV); whether the class-1 teacher has received pre-service training (PRETRAIN); the number of days he or she spent in non-

${ }^{24}$ Some of these village characteristics (e.g. distance from road and level of development) are among the independent variables in our regressions. 
teaching duties during the 28 days preceding the survey (TDAYSNT) ${ }^{25}$ an index of parent-teacher cooperation (PTCOOP); and whether the school building is water-proof (BWATERP).

One limitation of some of these indicators (particularly DAYS6 and TDAYSNT) is that they may reflect transient circumstances rather than durable characteristics of the school. For instance, TDAYS6 is an indicator of school activity during the week preceding the survey, and that too without adjustment for holidays or other disruptions unrelated to the quality of the school. This limitation is particularly serious when the left-hand side variable is 'grade attainment', which pertains to children (currently aged 13-18) who went through primary school several years before the survey.

Aside from those listed in Table 2, we tried a number of other school-quality indicators, e.g. whether the school conducts regular tests, whether the teachers are unionised, whether any teacher was absent on the day of the survey, the proportion of female teachers, the frequency of physical punishment, an index of teacher qualifications, and a dummy for the presence of a private school in the village. Though they usually had the 'right' sign, these variables had unstable coefficients, and were seldom statistically significant. To reduce multicollinearity problems, we dropped them from the regressions reported in the next section. In some cases (e.g. the teacher-absenteeism variable), the poor performance of these variables is likely to be related to the limitations mentioned in the preceding paragraph.

\section{Composite indices}

The school-quality indicators listed in Table 2 include two composite indices: INFRA and PTCOOP. The former is a relatively straightforward index of physical infrastructure (see Table $2 b$ for details). The latter is a tentative index of parent-teacher cooperation, calculated as an unweighted average of four dummy variables. The latter take value 1, respectively, if (1) the headmaster reported having approached the parents for help during the twelve months preceding the survey, (2) the headmaster is satisfied with parents' responses to his or her demands, (3) the school has a parent-teacher association, (4) the headmaster considers the parents' attitude towards the school as 'helpful'. The problem of transient influences obviously applies in this case, and it is interesting that in spite of that the parent-teacher cooperation variable has a significant positive influence on grade attainment.

\section{Aggregation over schools}

${ }^{25}$ The diversion of 'non-teaching duties' is a common complaint of teachers in rural India. Teachers are often mobilised, for instance, to help with the decennial census, the cattle census, vote counting, health programmes and literacy campaigns (see The PROBE Team 1999, chapter 5). 
A majority (77 per cent) of the sample villages have a single school. For villages with more than one school (usually two), the school-quality indicators listed in Table 2 were averaged across schools within a village, using the numbers of children enrolled in each school as weights. The value of an aggregated school-quality indicator calculated in this way may be interpreted as the level of school-quality which a child can expect to get, assuming that he or she is assigned at random between the different schools in the village, and that the probability of joining a particular school is proportional to current enrolment. In the special case of CTRATIO, we simply divided the estimated child population of the village by the total number of primary-grade teachers in the village.

\section{$\underline{\text { Parental motivation }}$}

Our regression variables include one indicator of parental motivation (IMPGIRL). This is a dummy variable taking value 1 if the main respondent answered 'yes' to the question 'is it important for a girl to be educated?', and 0 otherwise. ${ }^{26}$ It may be objected that negative answers to this question could reflect ex-post rationalization on the part of parents, rather than actual motivation: some parents might report that it is not important for their daughter to go to school simply to reconcile themselves to the fact that she is unable to go for other reasons. Note, however, that the question refers to 'a girl', not 'your daughter'. This phrasing reduces the problem of ex-post rationalization, without perhaps eliminating it entirely. It is also worth noting that IMPGIRL turns out to be a strong predictor of school participation for boys as well as for girls (see below).

\section{Estimation}

Since the dependent variables 'initial enrolment' and 'current enrolment' are both binary variables, the discrete-choice probit or logit model is a natural estimation framework. We employ the familiar binary logit, based on maximum likelihood methods. In the case of grade attainment, however, there is no obvious estimation procedure. If never-enrolled children are discarded, OLS estimates of grade attainment are vulnerable to selection bias. ${ }^{27}$ We considered a Heckman selectivity-correction model for grade attainment conditional on enrolment, but rejected this approach in the absence of credible exclusion restrictions (the latter involve identifying variables that affect the probability of enrolment but not grade attainment). As an alternative, we decided to retain the never-enrolled children and use an 'ordered logit' model, where grade attainment is

\footnotetext{
${ }^{26}$ The corresponding question for boys ('Is it important for a boy to be educated?') is of little use here, since 99 per cent of the respondents answered 'yes'.

${ }^{27}$ To illustrate the selection bias, suppose that poor parents only enrol children with high abilities. This could lead to a spurious impression that poor children are doing quite well at school; in other words, the coefficient of an income or wealth indicator in the grade-attainment equation would be biased downwards (given that 'abilities' are unobserved). In general, the selection bias arises from the fact that enrolled children have unobserved characteristics that affect grade attainment, and are correlated with observed characteristics, leading to a correlation between right-hand side variables and the error term in the grade-attainment equation.
} 
reorganised into three hierarchial categories. The categorical grade-attainment variable takes value 0 for never-enrolled children, 1 for ever-enrolled children who have not completed the primary stage (i.e. five years of schooling), and 2 for those who have completed the primary stage.

The statistical packages LIMDEP7 and STATA6 were used for estimation. The log likelihood function was well behaved, usually reaching its maximum within 7 newton iterations in all three models. The goodness of fit measures are also encouraging. The pseudo R-squares suggest that the explanatory power of the models is good compared to the norm for discrete choice models. In the tables below, we report robust t-values adjusted for cluster effects, i.e. the possibility of correlated errors across individual observations within each village (Deaton, 1997, p.77; Moulton, 1990).

\section{Main Findings: school attendance}

The basic regression results are presented in Tables 3, 4, and 5. Each table focuses on a different left-hand side variable: 'initial enrolment', 'current enrolment', and 'grade attainment' respectively (see section 4).

In each case, we present separate regressions for boys and girls. The 'girls' regressions tend to have a larger number of statistically significant coefficients than the 'boys' regressions. This makes sense, since there is far more variation on the left-hand side in the case of female children (especially for 'initial enrolment', which takes value 1 for all but a small minority of boys). For the same reason, the results obtained when boys and girls are pooled (and a 'gender' dummy is added on the right-hand side) are quite close to those applying to 'girls only'. For instance, in the few cases where a variable has a different sign in the male and female regressions (e.g. LANDOWN in Table 3), the sign of this variable is usually the same in the pooled regression as in the corresponding 'girls only' regression. ${ }^{28}$ In the pooled regressions, the gender dummy (male=1) is always positive and highly significant, indicating a sharp gender bias in school participation. ${ }^{29}$

Going back to the issues raised in section 3, a number of useful insights arise from the regressions presented in Tables 3 to 5. For expositional clarity, the remainder of this section

${ }^{28}$ The influence of male observations in the pooled regressions is somewhat greater in the 'grade attainment' regressions (Table 5). This is not surprising, since the variation in grade attainment among boys is much greater than the variation in 'initial enrolment' or even 'current enrolment'.

${ }^{29}$ This pattern is consistent with earlier research. A notable exception is Subramanian (1995), who finds little evidence of discrimination against girls in terms of household expenditure on schooling in four Indian states. In this connection, it is worth noting that, according to the PROBE survey, expenditure on schooling (conditional on enrolment) is somewhat higher for girls than for boys, mainly on account of the higher costs of 'uniforms and clothing'. This pattern, together with clear evidence of gender bias in school participation, highlights one limitation of the method used by Subramanian, i.e. that it does not allow for asymmetric needs between boys and girls. 
focuses on the 'initial enrolment' and 'current enrolment' regressions. These two schooling outcomes will be jointly referred to as 'participation'. 'Grade attainment' results are discussed in the next section.

Looking across Tables 3 and 4 in a given column, we find a high degree of consistency between the results pertaining to the two different left-hand side variables (e.g. sign reversals are uncommon). This is reassuring: if the results were spurious, we would not expect them to be robust to the choice of age group and school-participation indicator.

\section{$\underline{\text { Household variables }}$}

The 'household' variables tend to perform better than the 'school' or 'village' variables, not surprisingly since the household variables are more versatile indicators of the circumstances of a child. The household variables almost always have the expected sign and are often statistically significant (especially for girls). Variations of the baseline regressions indicate that their coefficients are quite robust.

As expected, the probability of school participation increases with parental education (both maternal and paternal), though mother's education does not have a significant effect on male school participation. In that sense, inter-generational 'cross-sex' effects are weaker than inter-generational 'same-sex' effects, much as in Jayachandran (1997). The largest inter-generational effect is that of maternal education on girls' school participation. ${ }^{30}$ Also as expected, household wealth (as captured by ASSET) enhances school participation for boys as well as girls, and the effect is highly significant for girls. However, consistent with our earlier discussion, land ownership (LANDOWN) has a negative sign for girls (not significant), and similarly with ownership of domestic animals (COWGOAT). The latter has a significant negative impact on girls' current enrolment. So does the dependency ratio (DEPEND), as one would expect not only because the latter is correlated with poverty but also because eldest daughters in households with many children are often expected to look after younger siblings at home (The PROBE Team, 1999, pp. 28-31).

Even after controlling for other household variables, children belonging to 'scheduled castes and scheduled tribes' (SC/ST) and 'other backward castes' (OBC) are less likely to go to school than children belonging to the general castes (default category). This applies particularly to girls: for boys, the effect is not statistically significant. Interestingly, the marginal effects suggest that the educational disadvantage is much the same among OBC and SC/ST children, though somewhat larger for the latter category in the case of initial enrolment: being SC/ST reduces a girl's probability of being initially enrolled by 8 percentage points, compared with a disadvantage of 6

\footnotetext{
${ }^{30}$ These patterns also hold if IMPGIRL is dropped from the regression.
} 
percentage points for OBC girls. ${ }^{31}$ The coefficient on the MUSLIM dummy is negative, but not statistically significant. Interestingly, this applies even if IMPGIRL is dropped from the regressions. This goes against the common notion that Muslim culture is inimical to schooling. The fact that school participation is lower among Muslims seems to have more to do with tangible disadvantages such as poverty and low levels of parental education.

Our indicator of parental motivation (IMPGIRL) is highly significant in all the regressions presented in Tables 3 and 4. The chance of a girl being currently enrolled rises by as much as 30 percentage points if her parents consider that education is 'important' for female children. Interestingly, the chance of a boy being currently enrolled also rises significantly (by 10 percentage points) with this motivation dummy. Even after allowing for an element of spuriousness here (e.g. due to the 'ex post rationalization' factor), the influence of parental motivation seems to be very strong in comparison with that of most other variables.

It is also worth noting that, when IMPGIRL is excluded from the regression, the coefficients of CASLAB, SCST, OBC and MUSLIM become larger, and have larger t-ratios. For instance, CASLAB has a significant negative coefficient in the 'current enrolment' regressions when IMPGIRL is excluded. In other words, the overall educational disadvantage of children belonging to underprivileged social groups is partly mediated by lower parental motivation. The fact that a disadvantage remains (especially for SC/ST children) even after controlling for parental motivation suggests that social discrimination in the schooling system may also be involved. The latter hypothesis is consistent with other findings of the PROBE survey (The PROBE Team, 1999, pp. 4951). The possible persistence of an overall bias against SC/ST children in the schooling system is all the more striking considering that pupil incentives are often targeted in their favour.

Finally, the marginal effects of the age dummies in Table 4 yield interesting information on drop-out rates. The probability of being at school is about 5 percentage points lower for a boy aged 12 than for a boy aged 6 (the 'default' age group). Considering that most boys are initially enrolled, this suggests that drop-out rates are much below the levels found in official data. According to the latter, for instance, 36 per cent of boys enrolled in class 1 do not complete class 5; this is difficult to reconcile with our marginal effects. The causes of bias in official data are discussed in The PROBE Team (1999, p. 92), where alternative estimates of drop-out rates are also given. The latter are highly consistent with the marginal effects reported in Table 4, for girls as well as for boys. Dropout rates, of course, are much higher for girls than for boys.

\section{$\underline{\text { School variables }}$}

The regressions in Tables 3 and 4 suggest that school variables have relatively little

${ }^{31}$ In the 'grade attainment' equation (Table 5), the coefficients of SC/ST and OBC do differ, but they are not statistically significant. 
influence on primary-school participation among boys. However, this influence is bound to be hard to capture, partly due to the low variation in male school participation in this data set, and partly due to the rudimentary nature of the 'school quality' indicators.

None of the school-quality variables are statistically significant in the 'current enrolment' regression for boys. In the 'initial enrolment' regression (again for boys), non-teaching duties (TDAYSNT) and the child-teacher ratio (CTRATIO) are statistically significant, with a negative sign as expected. The provision of a mid-day meal (GIVEMEAL) is also statistically significant, but with a puzzling negative sign. One possible explanation is that school meals are targeted at disadvantaged areas -- see below.

The school variables perform better in the corresponding regressions for girls. In both regressions ('initial enrolment' and 'current enrolment'), five out of nine school-quality indicators are significant (with the expected sign in each case, except INFRA). Three indicators are highly significant in both regressions.

Female school participation is about 15 percentage points higher when the local school provides a mid-day meal (GIVEMEAL) than when it does not; it is also higher when the village has a low child-teacher ratio (CTRATIO). There is also some evidence of a positive impact of teacher regularity and qualifications (as captured by DAYS6 and PRETRAIN), though these variables are statistically significant in only one of the two regressions. Like TLIVEV, these variables reflect relatively transient aspects of school quality, and it is understandable that they should have less important effects than, say, GIVEMEAL or CTRATIO, especially in the 'initial enrolment' equation.

The fact that GIVEMEAL has a significant positive coefficient and a large marginal effect in both female enrolment equations is of some practical importance, and we submitted it to further scrutiny. This finding turns out to survive alternative specifications of these equations (and it shows up again in the 'grade attainment' equation - see below). Nor is it likely to reflect the fact that school meals are targeted at villages that have favourable unobserved characteristics. In fact, the PROBE survey suggests that school meals are more likely to be targeted at disadvantaged areas. Consistent with this hypothesis, a regression of GIVEMEAL on village characteristics yields a negative coefficient for VDEVELOP (the village development index), and a positive coefficient for VDISROAD (distance from the nearest road). The coefficients, however are not statistically significant. The only statistically significant variable is VVEC (presence of a 'village education committee'), with a positive coefficient.

The school infrastructure index (INFRA) is statistically significant, with a negative sign (we continue to focus on the regressions for girls). This is the only seriously counter-intuitive aspect of the results. One possible explanation, here again, is that infrastructural facilities are targeted at 
villages with low school attendance rates. ${ }^{32}$ Another is that crowding in schools leads to dilapidation of the infrastructure (in both cases, some kind of 'reverse causation' is at work).

It is interesting to compare the coefficient of INFRA with that of BWATERP, a dummy variable indicating whether the school building is water-proof (a large majority of schools have leaking roofs). Water-proofness is important both because leaking roofs cause prolonged disruptions of school activity during the monsoon, and also as an indicator of infrastructural maintenance. The 'reverse causation' effects mentioned in the preceding paragraph are likely to be less serious in this case, and it is reassuring to find that BWATERP has a large, positive, and statistically significant effect on female school participation in both regressions. ${ }^{33}$

\section{$\underline{\text { Village variables }}$}

As with the school variables, the village variables (VVEC, VDISROAD, VDEVELOP and VWASSOC) have little influence on boys' school participation, with one exception: distance from the nearest road (VDISROAD) has a negative impact on 'initial enrolment'. Turning to girls' participation, the village development index (VDEVELOP) has a positive and statistically significant coefficient in both regressions. The dummy indicating whether the village has a women's association (VWASSOC) also has a positive coefficient, and is significant at the $10 \%$ level in the 'current enrolment' regression. However, some reverse causation may be involved here, in so far as women's associations tend to spring up in villages with relatively high levels of female education.

Finally, the presence of a village education committee (VEC) appears to have no significant impact on school participation. ${ }^{34}$ This is consistent with the notion that these committees are, in most cases, token institutions (The PROBE Team, 1999). It is also possible, however, that the positive effect of village education committees on school participation is entirely mediated by variables such as GIVEMEAL and IMPGIRL. As noted earlier, school meals are more common in villages that have a village education committee.

${ }^{32}$ Many of the items making up the infrastructure index (see Table 2b) have been supplied to the sample schools during the last ten years under Operation Blackboard. The latter may give special treatment to disadvantaged villages, in practice if not as a matter of policy.

33 Glewwe and Jacoby (1994) report a similar finding for Ghana, where leaky classrooms are associated with low cognitive achievements. The authors even argue that their estimates (combined with back-of-the-envelope cost calculations) have "uncovered the relative effectiveness of repairing school buildings over investments in instructional materials, such as books, desks and blackboards and in teacher quality" (pp. 862-3).

${ }^{34}$ Note that VECs are recent institutions. This is probably why they have virtually no effect on 'initial enrolment', though their effect on 'current enrolment' is more encouraging. 


\section{Main Findings: Grade Attainment}

The results for 'grade attainment' (Table 5 and Appendix 2) are largely similar to - and consistent with - those discussed in the preceding section for 'initial enrolment' and 'current enrolment'. For instance, much as before we find that (1) parental education matters, especially for girls, with the largest marginal effects pertaining to the influence of maternal education on girls' grade attainment; (2) high dependency ratios have an adverse effect on schooling; (3) mid-day meals, village development and the presence of a women's association have a positive effect on girls' attainments; and (4) pupil attainments are positively influenced by teacher attendance, infrastructural quality (as captured by BWATERP) and the child-teacher ratio. A few specific points are worth noting.

Social disadvantage: As noted earlier, children from SC/ST or OBC families have relatively low chances of being enrolled. The evidence on grade attainments is less clear-cut: in Table 5 (first column), the coefficient of SC/ST is negative but not significant, and that of OBC is not even negative. In the case of SC/ST children, the results in Table 5 are best regarded as consistent with those of Tables 3 and 4, in so far as the drop in t-value can be attributed to a smaller sample size. In the case of OBC children, however, Table 5 qualifies the earlier results.

Parent-teacher cooperation: Our index of parent-teacher cooperation, PTCOOP, has a positive and significant effect on grade attainment. This finding is particularly interesting in light of the rudimentary nature of this index, and is highly consistent with qualitative observations from the PROBE survey. 'School quality' may have far more to do with this kind of intangible input than with standard quantitative indicators such as physical infrastructure, teacher salaries or class size.

Mid-day meals: As with 'initial enrolment' and 'current enrolment', mid-day meals have a major positive effect on girls' grade attainment. The chances of completing primary education are 30 percentage points higher for girls living in villages with a mid-day meal than for other girls. As discussed in section 5, this does not seem to be due to the fact that mid-day meals are targeted at privileged villages. A more plausible explanation is simply that mid-day meals drive down the private costs of schooling. As observed by The PROBE Team (1999, p.97): '... parents are not generally opposed to female education, but they are reluctant to pay for it. School meals could make a big difference here, by reducing the private costs of schooling. ${ }^{35}$

35 In this connection, it is worth noting that female schooling is far more responsive than male schooling to the economic status of the household (as captured here by ASSET). For a similar finding in Pakistan, see Jensen (1999). 


\title{
7. Further Observations
}

\author{
$\underline{\text { Himachal Pradesh }}$
}

As mentioned in section 2, Himachal Pradesh has remarkably high levels of school participation by north Indian standards. On the other hand, if we re-run the baseline regressions after adding a dummy variable for Himachal Pradesh, this variable is not statistically significant (in some cases, it does not even have a positive sign). This suggests that the high rates of school participation in Himachal Pradesh are fully 'explained' by the household, school and village characteristics included in the regressions.

If school characteristics are dropped on the right-hand side, the regional dummy remains non-significant, suggesting that better school quality is not the main distinguishing feature of Himachal Pradesh. On the other hand, if village characteristics are dropped (with or without school variables being reinstated), the coefficient of the regional dummy becomes positive and significant. Thus, favourable village characteristics seem to play an important role in explaining high school participation in Himachal Pradesh. Household characteristics are also likely to play a role, but not a crucial one as the difference in household characteristics between Himachal Pradesh and other states is not very large - at least in terms of the observable variables included in this analysis.

To shed further light on these issues, Table 6 compares the means of the regression variables for Himachal Pradesh with the corresponding means for the whole sample. For each variable, the table also indicates how the difference between the Himachal Pradesh mean and the overall sample mean would shift the predicted value of 'current enrolment' (for boys and girls combined), based on the marginal coefficients reported in Table $4 .{ }^{36}$ Among the village and school variables, the largest positive shifts are contributed by the village development index (VDEVELOP), the dummy for women's associations (VWASSOC), and the infrastructural maintenance indicator (BWATERP). Levels of parental education and motivation are also higher in Himachal Pradesh. So is the parentteacher cooperation index, and while this has relatively little effect on current enrolment, it does play a significant part in raising 'grade attainment' in Himachal Pradesh. Similarly, lower childteacher ratios in Himachal Pradesh have a major effect on 'initial enrolment' among girls.

\section{Child-teacher ratios reexamined}

We briefly return to the possible problem of endogeneity of teacher inputs (see section 4). Alternative ways of dealing with this problem are investigated in Table 7, focusing on the 'current enrolment' regression for girls (similar findings apply to other regressions). The first column

${ }^{36}$ A more sophisticated decomposition of Himachal Pradesh's advantage, allowing for different regression coefficients in HP and elsewhere (e.g. using Oaxaca's method), is difficult to carry out due to the small number of observations for Himachal Pradesh. 
replicates Table 4, where we found that the child-teacher ratio has a negative effect on girls' enrolment.

Next, we abandon the assumption that CTRATIO is exogenous. One possible way forward is to drop this variable from the regression, and to interpret the equation as a 'reduced form': each coefficient measures the overall effect of a particular variable on school enrolment, including any possible effect arising from endogenous adjustments in teacher postings. As can be seen from the second regression in Table 7, the reduced-form coefficients are much the same as in the first column.

Finally, we searched for a suitable instrument for the child-teacher ratio. One plausible candidate is VDISROAD, the distance separating the village from the nearest road. This variable satisfies three crucial conditions. First, it is exogenous. Second, it is highly correlated with the child-teacher ratio: accessible villages have more teachers, because teachers lobby for convenient postings, with a fair degree of success. Third, there is no reason why VDISROAD should have a direct influence on school participation. It is true, of course, that remote villages tend to have lower school participation rates. But this is for reasons that are captured by other independent variables, e.g. lower levels of development, parental education and school quality. Distance from the nearest road per se is unlikely to matter. ${ }^{37}$

The results of the instrumental-variable approach are shown in the last column of Table 7. Comparing with the first column, we find that the coefficient of CTRATIO remains negative, with a larger absolute value but a smaller t-ratio (significant at the $10 \%$ level). The other coefficients are much the same as before.

These results are somewhat inconclusive. The fact that CTRATIO continues to have a negative effect in the IV equation alleviates the concern that the negative coefficient in the other equation might be spurious (i.e. reflect a feedback effect rather than the response of school participation to teacher inputs). On the other hand, if CTRATIO has an important impact on school participation, one would not expect the other coefficients to be so stable, unless CTRATIO is orthogonal to the other variables, which we know is not the case. The explanation seems to be that the effect of CTRATIO, though real, is small.

\section{Comparison with Vandana Sipahimalani}

${ }^{37}$ One qualification is that, even after controlling for the other variables listed in Table 6, school participation may be sensitive to the distance separating the village from the nearest secondary school (which is likely to be correlated, in turn, with distance from the nearest road). Note that VDISROAD having a significant coefficient in the 'initial enrolment' equation for boys (see Table 3) does not contradict the notion that VDISROAD actually has no influence on school participation: if CTRATIO in that equation is a contaminated variable, a valid instrument for it would pick up some of the effect of the 'true' CTRATIO. 
In an independent study of similar inspiration, Vandana Sipahimalani (1997) has investigated the determinants of school participation in rural India using household survey data collected by the National Council of Applied Economic Research in 1994. Her sample is much larger than ours (33,174 children aged 6-14), and covers all the major Indian states. Sipahimalani examines both 'initial enrolment' and 'grade attainment', using estimation techniques similar to those used in this paper (with some extra frills). Her results are broadly consistent with ours. A few specific points of convergence and contrast are noted here.

The results pertaining to household variables are much the same in both studies. Much as we do, Sipahimalani finds that parental education has a strong positive influence on school participation, and that same-sex effects (especially the effect of maternal education on girls' school participation) are particularly strong. Children from scheduled castes and scheduled tribes are at a disadvantage, not only for initial enrolment but also, in her sample, for grade attainment. There is a strong income effect, especially for girls.

A major contribution of Sipahimalani's study is to present strong evidence of the influence of school quality on school participation. School characteristics that have a significant positive influence on initial enrolment and grade attainment include the proportion of female teachers, the proportion of trained teachers, the proximity of schools, school meals, and other pupil incentives. It is plausible that Sipahimalani obtained stronger results in this respect because her sample is not only larger but also more diverse in terms of the school variables. ${ }^{38}$ In the PROBE states, most schools are in bad shape.

Taken together, Sipahimalani's study and ours lend much support to the notion that school quality matters a great deal, even after conditioning for many household characteristics. Much work remains to be done, however, in identifying the precise influence of specific aspects of school quality. In our regressions, a likelihood-ratio test on school variables invariably shows the latter to be jointly significant, but distinguishing between different types of school-quality effects is more difficult. To some extent this is as expected, since the most crucial school-quality variables (e.g. teacher motivation) remain unobserved, and this has the effect of inflating the standard errors on the other variables. Somewhat in contrast with Hanushek's (1995) assessment, identifying links between school participation and specific school inputs seems to be no easier than establishing similar relationships between school inputs and test scores.

${ }^{38}$ Note, however, that Sipahimalani does not correct standard errors for cluster effects. In our own work, we found that the $t$ statistics for school and village variables decline a good deal when these corrections are made. For instance, in the absence of corrections for cluster effects the parent-teacher cooperation index is significant (with a positive sign) in most regressions. 


\section{Concluding Remarks}

To conclude, a number of valuable insights emerge from this analysis.

First, the results lend support to a 'pluralist' view of the causes of educational deprivation in rural India, which gives due recognition to several key determinants of school participation: household resources, parental motivation, the returns to child labour, and school quality. We find evidence of each of these influences, as both common sense and elementary analysis would predict. The only qualification arises from mixed evidence on the relation between educational participation and infrastructural facilities.

Second, we find strong inter-generational effects (i.e. children of educated parents are more likely to go to school), even after controlling for a wide range of variables. Boys' schooling is more responsive to father's education than to mother's, and vice-versa for girls. Maternal education has a large positive effect on a daughter's chances of completing primary school.

Third, scheduled-caste children have an 'intrinsic disadvantage', in the sense that they are less likely to go to school than other children, even after controlling for household wealth, parental education and motivation, school quality, and related variables. This suggests the persistence of an overall bias against scheduled-caste children in the schooling system, in spite of positive discrimination in pupil incentives. We found no evidence of an intrinsic disadvantage among Muslim children.

Fourth, the high level of school participation in Himachal Pradesh is entirely accounted for by the variables included in this analysis, with village characteristics (e.g. the 'village development index' and the existence of a women's association) playing a key role in explaining the difference between Himachal Pradesh and other states. This finding is somewhat unexpected: field observations suggest that Himachal Pradesh's lead derives, at least partly, from qualitative aspects of the schooling system that are unlikely to be captured in this analysis (The PROBE Team, 1999, chapter 9). Further research on this 'success story' is likely to be rewarding.

Fifth, school meals have a major positive effect on female school participation. This finding is consistent with the perceptions of parents and teachers (The PROBE Team, p.95), and strengthens the case for extending school meal programmes (Drèze, 1998).

Finally, the results suggest that grade attainment is positively influenced by several schoolquality variables: teacher attendance, parent-teacher cooperation, infrastructural maintenance, and the child-teacher ratio. However, considerable measurement problems arise in capturing school quality. Facilities or even teacher inputs may not matter as much as the functioning of the schools, 
which is difficult to observe. The quest for reliable evidence on the relationship between school participation and different aspects of school quality continues. 


\section{References}

Angrist, J.D., and Lavy, V. (1996), 'Using Maimonides' Rule to Estimate the Effect of Class Size on Children's Academic Achievements', mimeo, Department of Economics, Hebrew University.

Bhatty, Kiran (1998), 'Educational Deprivation in India: A Survey of Field Investigations' Economic and Political Weekly, 4 July and 10 July.

Bhatty, K., De, A., Drèze, J.P., Shiva Kumar, A.K., Mahajan, A., Noronha, C., Pushpendra, Rampal, A., and Samson, M. (1997), 'Class Struggle', India Today, 13 October.

Boissiere, M., Knight, J., and Sabot, R. (1985), 'Earnings, Schooling, Ability, and Cognitive Skills', American Economic Review, 75.

Case, Anne, and Deaton, Angus (1997), 'School Quality and Educational Outcomes in South Africa', mimeo, Research Program in Development Studies, Princeton University.

Campaign Against Child Labour (1997), 'Public Hearing on Child Labour, Reference Kit', document prepared for the $2^{\text {nd }}$ National Convention on Child Labourers, New Delhi.

Deaton, Angus (1997), The Analysis of Household Surveys (Baltimore: Johns Hopkins).

Drèze, Jean (1998), 'Primary Priorities: Managing Meals', Times of India, April.

Drèze, Jean, Peter Lanjouw, and Naresh Sharma (1997), 'Credit in Rural India: A Case Study', Discussion Paper No. 6, Development Economics Research Programme, STICERD, London School of Economics.

Drèze, Jean, and Sharma, Naresh (1998), 'Palanpur: Population, Economy, Society', in Lanjouw, P., and Stern, N.H. (eds.), Economic Development in Palanpur over Five Decades (Delhi and Oxford: Oxford University Press).

Duraisamy, P. (1992), 'Gender, Intrafamily Allocation of Resources and Child Schooling in South India’, Discussion Paper No. 667, Economic Growth Center, Yale University.

Duraisamy, P., and Duraisamy, M. (1991), 'Impact of Public Programs on Fertility and Gender Specific Investment in Human Capital of Children in Rural India', in Schultz, T.P. (ed.), Research in Population Economics, 7.

Fuller, Bruce (1986), 'Raising School Quality in Developing Countries: What Investments Boost Learning?', World Bank Discussion Paper No. 2, Washington D.C.

Glewwe, Paul, and Jacoby, Hanan (1994), 'Student Achievement and Schooling Choice in Low Income Countries: Evidence from Ghana', Journal of Human Resources, 29.

Hanushek, Eric (1986), 'The Economics of Schooling: Production and Efficiency in Public Schools', Journal of Economic Literature, 24. 
Hanushek, Eric (1995), 'Interpreting Recent Research on Schooling in Developing Countries', World Bank Research Observer, 10.

Heyneman, S., and Loxley, W. (1982), 'Influences on Academic Achievement Across High and Low Income Countries: A Re-Analysis of IEA data', Sociology of Education, 55.

Heyneman, S., and Loxley, W. (1983), 'The Effect of Primary School Quality on Academic Achievement Across Twenty Nine High and Low Income Countries', American Journal of Sociology, 88.

International Institute for Population Sciences (1995), National Family Health Survey 1992-3 (Bombay: IIPS).

Jayachandran, Usha (1997), 'The Determinants of Primary Education in India', M.Sc. thesis, Department of Economics, Delhi School of Economics.

Jensen, Robert T. (1999), 'Patterns, Causes and Consequences of Child Labour in Pakistan', mimeo, Center for International Development, Harvard University.

Kingdon, Geeta Gandhi (1994), 'An Economic Evaluation of School Management-Types in Urban India: A Case Study of Uttar Pradesh', D.Phil. thesis, St Antony’s College, University of Oxford.

Kingdon, Geeta Gandhi (1996), 'Student Achievement and Teacher Pay', Discussion Paper 76, Development Economics Research Programme, STICERD, London School of Economics.

Kingdon, Geeta Gandhi (1998), 'Education of Females in India: Determinants and Economic Consequences: A Case Study of Urban Uttar Pradesh', mimeo, McNamara Fellowships Office, Economic Development Institute of the World Bank, Washington DC.

Kingdon, Geeta Gandhi, and Unni, Jeemol (1998), 'Education and Women's Labour Market Outcomes in India: An Analysis Using NSS Household Data', Discussion Paper 202, Applied Economics Series, Institute of Economics and Statistics, University of Oxford.

Labenne, Sophie (1995), 'Analyse Econometrique du Travail des Enfants en Inde', M.Sc. thesis, Department of Economics, Université de Namur, Belgium.

Labenne, Sophie (1997), 'The Determinants of Child Labour in India', mimeo, Department of Economics, Université de Namur, Belgium.

Mehrotra, Nidhi (forthcoming), 'Primary Schooling in Rural India: Determinants of Demand', PhD thesis, University of Chicago.

Moulton, Brent (1990), "An Illustration of a Pitfall in Estimating the Effects of Aggregate Variables in Micro Units", Review of Economics and Statistics, 72.

National Council of Applied Economic Research (1996a), Human Development Profile of India: Inter State and Inter Group Differentials. Volume I: Main Report. (New Delhi: NCAER). 
National Council of Applied Economic Research (1996b), Human Development Profile of India: Inter State and Inter Group Differentials. Volume II: Statistical Tables. (New Delhi: NCAER).

National Council of Educational Research and Training (1997), Sixth All-India Educational Survey (New Delhi: NCERT).

National Sample Survey Organisation (1997), 'Economic Activities and School Attendance by Children of India (Fifth Quinquennial Survey, NSS 50th round, 1993-94)', Report No. 412, NSSO, New Delhi.

Rao, Vijayendra (1998), 'Wife-Abuse, its Causes and its Impact on Intra-Household Resource Allocation in Rural Karnataka: A 'Participatory' Econometric Analysis', in Krishnaraj, M., Sudarshan, R., and Shariff, A. (eds.), Gender, Population and Development (Delhi: Oxford University Press).

The PROBE Team (1999), Public Report on Basic Education in India (New Delhi: Oxford University Press).

Sipahimalani, Vandana (1997), 'Education in the Rural Indian Household: A Gender Based Perspective', mimeo, Department of Economics, Yale University.

Subramanian, Shankar (1995), 'Gender Discrimination in Intra-Household Allocation in India', mimeo, Department of Economics, Cornell University. 
Table 2a

Mean values of regression variables

\begin{tabular}{|c|c|c|c|c|c|c|c|c|c|}
\hline \multirow[t]{2}{*}{ Variable } & \multicolumn{3}{|c|}{$\begin{array}{l}\text { Children 5-18 years old } \\
\text { (pertaining to Table 3) }\end{array}$} & \multicolumn{3}{|c|}{$\begin{array}{l}\text { Children 5-12 years old } \\
\text { (pertaining to Table 4) }\end{array}$} & \multicolumn{3}{|c|}{$\begin{array}{l}\text { Children 13-18 years old } \\
\text { (pertaining to Table 5) }\end{array}$} \\
\hline & All & Boys & Girls & All & Boys & Girls & All & Boys & Girls \\
\hline \multicolumn{10}{|c|}{ Individual characteristics } \\
\hline MALE & 0.560 & 1.000 & 0.000 & 0.570 & 1.000 & 0.000 & 0.527 & 1.000 & 0.000 \\
\hline AGE & 9.836 & 9.836 & 9.835 & & & & 15.020 & & \\
\hline AGESQ & 109.300 & 109.000 & 109.600 & & & & 228.200 & & \\
\hline AGE5 & & & & 0.122 & 0.107 & 0.142 & & & \\
\hline AGE7 & & & & 0.162 & 0.161 & 0.164 & & & \\
\hline AGE8 & & & & 0.155 & 0.150 & 0.162 & & & \\
\hline AGE9 & & & & 0.113 & 0.120 & 0.105 & & & \\
\hline AGE10 & & & & 0.119 & 0.132 & 0.103 & & & \\
\hline AGE11 & & & & 0.092 & 0.098 & 0.084 & & & \\
\hline AGE12 & & & & 0.104 & 0.100 & 0.110 & & & \\
\hline AGE14 & & & & & & & 0.224 & 0.201 & 0.249 \\
\hline AGE15 & & & & & & & 0.162 & 0.152 & 0.173 \\
\hline AGE16 & & & & & & & 0.167 & 0.162 & 0.173 \\
\hline AGE17\&18 & & & & & & & 0.217 & 0.259 & 0.170 \\
\hline \multicolumn{10}{|c|}{ Household characteristics } \\
\hline EDU_MO & 1.291 & 1.134 & 1.490 & 1.353 & 1.213 & 1.539 & 1.084 & 0.855 & 1.340 \\
\hline EDU_FA & 5.139 & 4.890 & 5.454 & 5.288 & 5.092 & 5.548 & 4.665 & 4.188 & 5.195 \\
\hline CASLAB & 0.159 & 0.167 & 0.147 & 0.164 & 0.172 & 0.153 & 0.139 & 0.148 & 0.130 \\
\hline JOB & 0.103 & 0.090 & 0.119 & 0.095 & 0.080 & 0.114 & 0.129 & 0.125 & 0.133 \\
\hline ASSET & 10.080 & 9.497 & 10.820 & 9.461 & 8.848 & 10.270 & 12.120 & 11.810 & 12.460 \\
\hline PCCRMS & 1.324 & 1.224 & 1.453 & 1.284 & 1.212 & 1.380 & 1.464 & 1.266 & 1.684 \\
\hline COWGOAT & 3.491 & 3.522 & 3.452 & 3.467 & 3.477 & 3.455 & 3.575 & 3.685 & 3.453 \\
\hline LANDOWN & 3.661 & 3.525 & 3.833 & 3.578 & 3.444 & 3.756 & 3.943 & 3.820 & 4.080 \\
\hline DEPEND & 1.448 & 1.388 & 1.525 & 1.439 & 1.386 & 1.510 & 1.478 & 1.394 & 1.571 \\
\hline MUSLIM & 0.099 & 0.106 & 0.091 & 0.101 & 0.107 & 0.094 & 0.092 & 0.102 & 0.082 \\
\hline SCST & 0.320 & 0.328 & 0.310 & 0.326 & 0.332 & 0.318 & 0.299 & 0.310 & 0.286 \\
\hline $\mathrm{OBC}$ & 0.301 & 0.293 & 0.311 & 0.296 & 0.286 & 0.309 & 0.316 & 0.318 & 0.314 \\
\hline \multirow{2}{*}{\multicolumn{10}{|c|}{ Community characteristics }} \\
\hline & & & & & & & & & \\
\hline VVEC & 0.551 & 0.534 & 0.573 & 0.540 & 0.523 & 0.564 & 0.589 & 0.575 & 0.603 \\
\hline VDISROAD & 3.364 & 3.484 & 3.212 & 3.442 & 3.570 & 3.271 & 3.092 & 3.152 & 3.025 \\
\hline VDEVELOP & 1.389 & 1.295 & 1.507 & 1.371 & 1.292 & 1.475 & 1.448 & 1.310 & 1.601 \\
\hline VWASSOC & 0.128 & 0.111 & 0.150 & 0.126 & 0.112 & 0.144 & 0.137 & 0.109 & 0.167 \\
\hline \multicolumn{10}{|l|}{ School characteristics } \\
\hline GIVEMEAL & 0.085 & 0.082 & 0.088 & 0.081 & 0.075 & 0.087 & 0.098 & 0.107 & 0.088 \\
\hline INFRA & 7.270 & 7.145 & 7.429 & 7.283 & 7.125 & 7.491 & 7.233 & 7.210 & 7.258 \\
\hline DAYS6 & 0.342 & 0.341 & 0.343 & 0.342 & 0.340 & 0.345 & 0.342 & 0.346 & 0.337 \\
\hline TLIVEV & 0.239 & 0.247 & 0.229 & 0.242 & 0.251 & 0.229 & 0.232 & 0.234 & 0.230 \\
\hline PRETRAIN & 0.696 & 0.692 & 0.702 & 0.695 & 0.686 & 0.705 & 0.702 & 0.710 & 0.694 \\
\hline TDAYSNT & 1.330 & 1.190 & 1.509 & 1.325 & 1.139 & 1.572 & 1.347 & 1.374 & 1.317 \\
\hline РТСООР & 1.359 & 1.340 & 1.382 & 1.360 & 1.349 & 1.375 & 1.356 & 1.311 & 1.405 \\
\hline BWATERP & 0.342 & 0.339 & 0.346 & 0.356 & 0.357 & 0.356 & 0.293 & 0.275 & 0.314 \\
\hline CTRATIO & 72.000 & 74.970 & 68.220 & 72.570 & 75.060 & 69.280 & 70.100 & 74.580 & 65.110 \\
\hline
\end{tabular}


Table 2b

Description of variables

\begin{tabular}{|c|c|}
\hline Variable & Description \\
\hline \multicolumn{2}{|c|}{ Individual and household characteristics } \\
\hline MALE & Dummy variable: 1 for boys, 0 for girls \\
\hline AGE5 to AGE17 & Age dummies: 1 for children of relevant age (e.g. five for AGE5), 0 otherwise \\
\hline AGE_CH & Child's age in years \\
\hline AGES̄Q & Square of child's age in year \\
\hline EDU_MO & Years of education of mother \\
\hline EDU_FA & Years of education of father \\
\hline CASLAB & Dummy: 1 if the household's main occupation is casual labour, 0 otherwise \\
\hline JOB & Dummy: 1 if household's main occupation is regular wage employment, 0 otherwise \\
\hline ASSET & $\begin{array}{l}\text { Index of assets owned by the household constructed as follows from owned assets: } \\
\text { asset }=(2 * \text { number of watches })+(5 * \text { number of cycles })+(2 * \text { number of radios })+(7 * \text { number of televisions })+(50 * \text { number of motorbikes })\end{array}$ \\
\hline PCCRMS & Number of pucca rooms in the house \\
\hline COWGOAT & Total number of cows, buffaloes, and goats owned by the household \\
\hline LANDOWN & Amount of land owned by the household, in acres \\
\hline DEPEND & Dependency ratio in the household: number of children (age 0-18) divided by number of adults \\
\hline MUSLIM & Dummy: 1 for Muslim households, 0 otherwise \\
\hline SCST & Dummy: 1 if household belongs to a schedule caste or schedule tribe, 0 otherwise \\
\hline $\mathrm{OBC}$ & Dummy: 1 if household belongs to an 'other backward caste', 0 otherwise \\
\hline IMPGIRL & Dummy: 1 if main respondent answers 'yes' to the question 'is it important for a girl to be educated?'; 0 otherwise \\
\hline \multicolumn{2}{|l|}{ Village characteristics } \\
\hline VVEC & Dummy: 1 if village has a Village Education Committee, 0 otherwise \\
\hline VDISROAD & Distance to nearest pucca road from the village centre, in kilometres \\
\hline VDEVELOP & $\begin{array}{l}\text { Village development index: the variables VELEC (village has electricity), VPOST (village has a post office), VPIPEW (village has piped water), and VPHONE (village has a } \\
\text { phone) each take the value } 1 \text { if the village has the facility and } 0 \text { if it doesn't. Then VDEVELOP = VELEC+VPOST+VPIPEW+VPHONE. }\end{array}$ \\
\hline VWASSOC & Dummy: 1 if village has a mahila mandal (women's association), 0 otherwise \\
\hline \multicolumn{2}{|l|}{ School characteristics } \\
\hline GIVEMEAL & Dummy: 1 if the school provides a mid-day meal, 0 otherwise \\
\hline INFRA & $\begin{array}{l}\text { Index of school infrastructure, calculated as a weighted sum of twelve dummy variables indicating whether the following items are available and functional: drinking water, toilet, } \\
\text { blackboard, chalk, maps or charts, library, electricity, fan, toys, science kit, playground, musical instruments. The weights are: } 1 \text { for the first six items, } 2 \text { for the other six. }\end{array}$ \\
\hline DAYS6 & Dummy: 1 if school was open for 6 days out of the past 7 days, 0 otherwise \\
\hline TLIVEV & Dummy: 1 if the class- 1 teacher lives in the village, 0 otherwise \\
\hline PRETRAIN & Dummy: 1 if the class- 1 teacher has pre-service training, 0 otherwise \\
\hline TDAYSNT & Number of days spent by the class- 1 teacher in non-teaching duties in the preceding 4 weeks \\
\hline PTCOOP & $\begin{array}{l}\text { Index of parent-teacher cooperation, constructed as an unweighted sum of four dummy variables: PATTIT (headteacher considers that the attitude of parents towards the school is } \\
\text { 'helpful'); PSUPPORT (headteacher approached the parents for help in the preceding year); PCOOP (parents' response to request for help was positive); and PTA (school has a } \\
\text { parent-teacher association). }\end{array}$ \\
\hline BWATERP & Dummy: 1 if the school building is water-proof, 0 otherwise. \\
\hline CTRATIO & $\begin{array}{l}\text { 'Child-teacher ratio': number of children aged 6-11 divided by number of teachers appointed in primary sections. The number of children aged 6-11 was calculated as } \\
0.14 * \text { VPOP, where VPOP is the village population and } 0.14 \text { is the } 1991 \text { census estimate of the proportion of the population in this age group in the PROBE states. }\end{array}$ \\
\hline
\end{tabular}


Table 3

Binary logit of initial enrolment (5-18 years)

\begin{tabular}{|c|c|c|c|c|c|c|c|c|c|c|c|c|}
\hline Variable & coefficient & $\begin{array}{c}\text { All } \\
\text { robust } \\
\text { t-value } \\
\end{array}$ & & $\begin{array}{r}\text { marginal } \\
\text { effect }\end{array}$ & coefficient & $\begin{array}{l}\text { Boys } \\
\text { robust } \\
\text { t-value } \\
\end{array}$ & & $\begin{array}{r}\text { marginal } \\
\text { effect }\end{array}$ & coefficient & $\begin{array}{l}\text { Girls } \\
\text { robust } \\
\text { t-value } \\
\end{array}$ & & $\begin{array}{r}\text { marginal } \\
\text { effect }\end{array}$ \\
\hline _cons & -5.9531 & -7.64 & $* *$ & -0.524 & -6.7880 & -5.90 & $* *$ & -0.406 & -4.5476 & -5.53 & $* *$ & -0.566 \\
\hline age_ch & 1.0838 & 9.58 & $* *$ & 0.095 & 1.5357 & 9.07 & $* *$ & 0.092 & 0.7741 & 5.98 & $* *$ & 0.096 \\
\hline agesq & -0.0473 & -9.87 & $* *$ & -0.004 & -0.0665 & -9.21 & $* *$ & -0.004 & -0.0344 & -5.84 & $* *$ & -0.004 \\
\hline edu_mo & 0.1467 & 3.31 & $* *$ & 0.013 & 0.0492 & 0.74 & & 0.003 & 0.1942 & 2.84 & $* *$ & 0.024 \\
\hline edu_fa & 0.1047 & 4.86 & $* *$ & 0.009 & 0.0697 & 2.05 & $* *$ & 0.004 & 0.1344 & 6.18 & ** & 0.017 \\
\hline caslab & -0.1840 & -0.97 & & -0.016 & -0.3297 & -1.19 & & -0.020 & -0.0466 & -0.20 & & -0.006 \\
\hline job & 0.1243 & 0.47 & & 0.011 & 0.0565 & 0.16 & & 0.003 & 0.1593 & 0.40 & & 0.020 \\
\hline asset & 0.0277 & 2.84 & $* *$ & 0.002 & 0.0345 & 1.47 & & 0.002 & 0.0284 & 2.92 & $* *$ & 0.004 \\
\hline pccrms & 0.0468 & 1.00 & & 0.004 & 0.0745 & 1.08 & & 0.004 & 0.0211 & 0.34 & & 0.003 \\
\hline cowgoat & -0.0152 & -0.74 & & -0.001 & 0.0162 & 0.61 & & 0.001 & -0.0330 & -1.60 & & -0.004 \\
\hline landown & -0.0022 & -0.13 & & 0.000 & 0.0184 & 0.66 & & 0.001 & -0.0178 & -0.75 & & -0.002 \\
\hline depend & -0.2168 & -2.58 & $* *$ & -0.019 & 0.0765 & 0.52 & & 0.005 & -0.4306 & -3.73 & $* *$ & -0.054 \\
\hline muslim & -0.2824 & -1.18 & & -0.025 & -0.2951 & -0.73 & & -0.018 & -0.4650 & -1.42 & & -0.058 \\
\hline scst & -0.3182 & -1.67 & $*$ & -0.028 & -0.1330 & -0.54 & & -0.008 & -0.6267 & -2.49 & $* *$ & -0.078 \\
\hline$o b c$ & -0.3284 & -1.55 & & -0.029 & -0.3323 & -1.38 & & -0.020 & -0.4689 & -1.67 & $*$ & -0.058 \\
\hline impgir & 1.2562 & 5.70 & $* *$ & 0.111 & 1.1387 & 4.10 & $* *$ & 0.068 & 1.5510 & 5.49 & $* *$ & 0.193 \\
\hline vvec & 0.0222 & 0.11 & & 0.002 & 0.0121 & 0.05 & & 0.001 & 0.0344 & 0.14 & & 0.004 \\
\hline vdisroad & -0.0073 & -0.30 & & -0.001 & -0.0601 & -2.36 & $* *$ & -0.004 & 0.0344 & 1.07 & & 0.004 \\
\hline vdevelop & 0.2284 & 2.88 & $* *$ & 0.020 & 0.0744 & 0.76 & & 0.004 & 0.2975 & 3.01 & $* *$ & 0.037 \\
\hline vwassoc & 0.2182 & 0.61 & & 0.019 & -0.2173 & -0.64 & & -0.013 & 0.5403 & 1.18 & & 0.067 \\
\hline givemeal & 0.0086 & 0.02 & & 0.001 & -0.9290 & -2.50 & $* *$ & -0.055 & 1.0820 & 2.58 & $* *$ & 0.135 \\
\hline infra & -0.0410 & -1.54 & & -0.004 & -0.0185 & -0.52 & & -0.001 & -0.0528 & -1.78 & * & -0.007 \\
\hline days6 & 0.2543 & 1.40 & & 0.022 & 0.2869 & 1.25 & & 0.017 & 0.2206 & 0.97 & & 0.027 \\
\hline tlivev & -0.0812 & -0.30 & & -0.007 & -0.0957 & -0.34 & & -0.006 & 0.0279 & 0.09 & & 0.003 \\
\hline pretrain & 0.3333 & 1.19 & & 0.029 & 0.2194 & 0.67 & & 0.013 & 0.5743 & 1.74 & * & 0.071 \\
\hline tdaysnt & -0.0371 & -1.77 & $*$ & -0.003 & -0.0499 & -2.84 & $* *$ & -0.003 & -0.0350 & -1.12 & & -0.004 \\
\hline ptcoop & 0.0649 & 0.72 & & 0.006 & 0.0682 & 0.61 & & 0.004 & 0.0632 & 0.54 & & 0.008 \\
\hline bwaterp & 0.5701 & 2.89 & $* *$ & 0.050 & 0.1501 & 0.62 & & 0.009 & 0.9666 & 3.97 & $* *$ & 0.120 \\
\hline ctratio & -0.0029 & -3.72 & $* *$ & 0.000 & -0.0022 & -2.33 & $* *$ & 0.000 & -0.0046 & -4.16 & $* *$ & -0.001 \\
\hline male & 1.3459 & 8.35 & $* *$ & 0.119 & & & & & & & & \\
\hline $\log \mathrm{L}$ & & -1113.97 & & & & -511.44 & & & & -542.99 & & \\
\hline Restricted Log L & & -1506.67 & & & & -668.65 & & & & -793.88 & & \\
\hline Pseudo R-square & & 0.2606 & & & & 0.2351 & & & & 0.3160 & & \\
\hline $\mathrm{N}$, mean of dep var & & $3191,0.819$ & & & & $1787,0.8763$ & & & & $1404,0.747$ & & \\
\hline
\end{tabular}


Table 4

Binary logit of current enrolment (5-12 years)

\begin{tabular}{|c|c|c|c|c|c|c|c|c|c|c|c|}
\hline Variable & coefficient & $\begin{array}{l}\text { All } \\
\text { robust } \\
\text { t-value }\end{array}$ & & $\begin{array}{r}\text { marginal } \\
\text { Effect }\end{array}$ & coefficient & $\begin{array}{l}\text { Boys } \\
\text { robust } \\
\text { t-value }\end{array}$ & $\begin{array}{r}\text { marginal } \\
\text { Effect }\end{array}$ & coefficient & $\begin{array}{l}\text { Girls } \\
\text { robust } \\
\text { t-value }\end{array}$ & & $\begin{array}{r}\text { marginal } \\
\text { Effect }\end{array}$ \\
\hline _cons & -0.2868 & -0.50 & & -0.032 & 0.8154 & 1.12 & 0.069 & -0.6870 & -0.99 & & -0.106 \\
\hline age5 & -2.5303 & $-8.82 *$ & $* *$ & -0.283 & -2.8106 & $-7.02 * *$ & -0.239 & -2.1675 & -5.26 & $* *$ & -0.335 \\
\hline age7 & 0.1523 & 0.61 & & 0.017 & 0.3421 & 1.09 & 0.029 & 0.1267 & 0.31 & & 0.020 \\
\hline age8 & -0.2037 & -1.01 & & -0.023 & 0.4624 & 1.46 & 0.039 & -0.6441 & -2.00 & $* *$ & -0.099 \\
\hline age9 & -0.2162 & -0.80 & & -0.024 & -0.1464 & -0.38 & -0.012 & -0.1810 & -0.47 & & -0.028 \\
\hline age10 & -0.4576 & $-2.03 *$ & ** & -0.051 & -0.2112 & -0.68 & -0.018 & -0.7286 & -2.23 & $* *$ & -0.113 \\
\hline age11 & -0.6105 & $-2.36 *$ & ** & -0.068 & -0.3393 & -0.80 & -0.029 & -0.8717 & -2.40 & $* *$ & -0.135 \\
\hline age12 & -0.7799 & $-3.16 *$ & $* *$ & -0.087 & -0.5282 & -1.48 & -0.045 & -1.1847 & -2.74 & $* *$ & -0.183 \\
\hline edu_mo & 0.1397 & $3.32 *$ & ** & 0.016 & 0.0667 & 1.30 & 0.006 & 0.1773 & 2.54 & ** & 0.027 \\
\hline edu_fa & 0.1085 & $5.23 *$ & $* *$ & 0.012 & 0.1069 & $3.72 * *$ & 0.009 & 0.1218 & 4.58 & $* *$ & 0.019 \\
\hline caslab & -0.3210 & -1.46 & & -0.036 & -0.2747 & -0.95 & -0.023 & -0.3865 & -1.43 & & -0.060 \\
\hline job & 0.1497 & 0.54 & & 0.017 & 0.3434 & 0.87 & 0.029 & 0.0475 & 0.13 & & 0.007 \\
\hline asset & 0.0306 & $3.02 *$ & ** & 0.003 & 0.0198 & 0.96 & 0.002 & 0.0353 & 3.26 & $* *$ & 0.005 \\
\hline pccrms & 0.0519 & 0.95 & & 0.006 & 0.0662 & 0.92 & 0.006 & 0.0487 & 0.62 & & 0.008 \\
\hline cowgoat & -0.0508 & $-1.80 *$ & $*$ & -0.006 & -0.0198 & -0.47 & -0.002 & -0.0853 & -2.11 & $* *$ & -0.013 \\
\hline landown & 0.0062 & 0.39 & & 0.001 & 0.0163 & 0.63 & 0.001 & 0.0069 & 0.29 & & 0.001 \\
\hline depend & -0.2137 & $-1.92 *$ & * & -0.024 & -0.1006 & -0.58 & -0.009 & -0.3294 & -2.17 & $* *$ & -0.051 \\
\hline muslim & -0.1986 & -0.74 & & -0.022 & -0.3240 & -0.81 & -0.028 & -0.2029 & -0.59 & & -0.031 \\
\hline scst & -0.5102 & $-2.35 *$ & ** & -0.057 & -0.4116 & -1.37 & -0.035 & -0.7135 & -2.67 & $* *$ & -0.110 \\
\hline$o b c$ & -0.4757 & $-2.26 *$ & ** & -0.053 & -0.3861 & -1.40 & -0.033 & -0.6657 & -2.55 & $* *$ & -0.103 \\
\hline impgir & 1.3187 & $5.68 *$ & ** & 0.147 & 1.1191 & $3.54 * *$ & 0.095 & 1.9811 & 6.68 & $* *$ & 0.306 \\
\hline vvec & 0.2109 & 1.09 & & 0.024 & 0.2689 & 1.00 & 0.023 & 0.1088 & 0.42 & & 0.017 \\
\hline vdisroad & 0.0077 & 0.28 & & 0.001 & -0.0100 & -0.39 & -0.001 & 0.0233 & 0.56 & & 0.004 \\
\hline vdevelop & 0.2196 & $2.94 *$ & ** & 0.025 & 0.0841 & 0.88 & 0.007 & 0.2989 & 2.96 & ** & 0.046 \\
\hline vwassoc & 0.2965 & 0.97 & & 0.033 & -0.0276 & -0.09 & -0.002 & 0.7244 & 1.73 & $*$ & 0.112 \\
\hline givemeal & 0.2366 & 0.71 & & 0.026 & -0.3232 & -0.84 & -0.027 & 1.0603 & 2.29 & $* *$ & 0.164 \\
\hline infra & -0.0541 & $-2.06 *$ & $* *$ & -0.006 & -0.0357 & -0.92 & -0.003 & -0.0640 & -2.17 & $* *$ & -0.010 \\
\hline days6 & 0.2586 & 1.41 & & 0.029 & -0.0550 & -0.25 & -0.005 & 0.5950 & 2.23 & $* *$ & 0.092 \\
\hline tlivev & -0.1624 & -0.64 & & -0.018 & -0.1030 & -0.42 & -0.009 & -0.1422 & -0.41 & & -0.022 \\
\hline pretrain & 0.3639 & 1.35 & & 0.041 & 0.4844 & 1.63 & 0.041 & 0.3626 & 1.00 & & 0.056 \\
\hline tdaysnt & -0.0228 & -1.30 & & -0.003 & -0.0152 & -0.81 & -0.001 & -0.0292 & -0.96 & & -0.005 \\
\hline ptcoop & 0.0443 & 0.51 & & 0.005 & 0.0386 & 0.32 & 0.003 & 0.0460 & 0.40 & & 0.007 \\
\hline bwaterp & 0.5786 & $2.81 *$ & *** & 0.065 & 0.2967 & 1.14 & 0.025 & 0.9894 & 3.18 & ** & 0.153 \\
\hline ctratio & -0.0012 & -1.34 & & 0.000 & -0.0001 & -0.10 & 0.000 & -0.0029 & -2.27 & $* *$ & 0.000 \\
\hline male & 1.2451 & $7.64 *$ & ** & 0.139 & & & & & & & \\
\hline $\log \mathrm{L}$ & & -908.63 & & & & -457.85 & & & -410.82 & & \\
\hline Restricted Log L & & -1283.34 & & & & -611.00 & & & -639.55 & & \\
\hline Pseudo R-square & & 0.2920 & & & & 0.2506 & & & 0.3576 & & \\
\hline $\mathrm{N}$, mean of dep var & & $2445,0.7816$ & & & & $1393,0.8406$ & & & $1052,0.703$ & & \\
\hline
\end{tabular}


Table 5

Ordered logit model of grade attainment (13-18 year olds)

(no schooling $=0 ; 1-4$ years of schooling $=1 ; \geq 5$ years of schooling $=2$ )

\begin{tabular}{|c|c|c|c|c|c|c|c|c|c|c|c|c|}
\hline Variable & coefficient & $\begin{array}{c}\text { All } \\
\text { robust } \\
\text { t-value }\end{array}$ & & $\begin{array}{r}\text { marginal effect } \\
\text { p }(>=\text { grade5) }\end{array}$ & coefficient & $\begin{array}{l}\text { Boys } \\
\text { robust } \\
\text { t-value }\end{array}$ & & $\begin{array}{r}\text { marginal effect } \\
\text { p }(>=\text { grade5) }\end{array}$ & coefficient & $\begin{array}{l}\text { Girls } \\
\text { robust } \\
\text { t-value }\end{array}$ & & $\begin{array}{r}\text { marginal effect } \\
\text { p }(>=\text { grade5) }\end{array}$ \\
\hline age14 & 0.4816 & 1.67 & $*$ & 0.084 & 0.4812 & 1.10 & & 0.051 & 0.4822 & 1.29 & & 0.112 \\
\hline age 15 & 0.0940 & 0.33 & & 0.014 & -0.3305 & -0.81 & & -0.042 & 0.3070 & 0.81 & & 0.071 \\
\hline age16 & 0.2856 & 0.95 & & 0.047 & 0.3742 & 0.80 & & 0.039 & -0.1476 & -0.38 & & -0.034 \\
\hline age $17 \& 18$ & 0.1188 & 0.46 & & 0.016 & -0.0383 & -0.11 & & -0.010 & 0.2678 & 0.66 & & 0.062 \\
\hline edu_mo & 0.3755 & 3.58 & $* *$ & 0.069 & 0.3860 & 1.64 & $*$ & 0.045 & 0.3731 & 3.08 & $* *$ & 0.086 \\
\hline edu_fa & 0.1029 & 3.14 & $* *$ & 0.019 & 0.1101 & 2.02 & $* *$ & 0.013 & 0.1217 & 3.33 & $* *$ & 0.028 \\
\hline caslab & -0.0327 & -0.11 & & 0.003 & -0.3754 & -0.88 & & -0.036 & 0.4156 & 1.28 & & 0.096 \\
\hline job & 0.1235 & 0.29 & & 0.019 & -0.3284 & -0.54 & & -0.041 & 0.1460 & 0.25 & & 0.034 \\
\hline asset & 0.0099 & 1.22 & & 0.002 & 0.0003 & 0.02 & & 0.000 & 0.0178 & 1.85 & * & 0.004 \\
\hline pecrms & 0.0347 & 0.57 & & 0.006 & 0.3394 & 2.49 & $* *$ & 0.039 & -0.0534 & -0.75 & & -0.012 \\
\hline cowgoat & 0.0692 & 1.97 & $* *$ & 0.012 & 0.2012 & 2.72 & $* *$ & 0.023 & -0.0073 & -0.17 & & -0.002 \\
\hline landown & -0.0269 & -1.32 & & -0.005 & -0.0432 & -1.00 & & -0.005 & -0.0181 & -0.55 & & -0.004 \\
\hline depend & -0.1694 & -1.57 & & -0.034 & 0.0813 & 0.43 & & 0.005 & -0.4256 & -2.69 & $* *$ & -0.098 \\
\hline muslim & -0.3798 & -1.15 & & -0.060 & -0.6578 & -1.63 & & -0.067 & -0.3840 & -0.75 & & -0.089 \\
\hline scst & -0.4348 & -1.43 & & -0.083 & -0.3889 & -0.90 & & -0.049 & -0.4817 & -1.29 & & -0.111 \\
\hline$o b c$ & 0.1457 & 0.60 & & 0.023 & 0.3970 & 1.11 & & 0.040 & -0.1513 & -0.46 & & -0.035 \\
\hline impgir & 0.9250 & 3.15 & $* *$ & 0.175 & 1.0771 & 2.91 & $* *$ & 0.129 & 0.6606 & 1.63 & & 0.153 \\
\hline vvec & -0.2163 & -0.92 & & -0.042 & -0.2749 & -0.81 & & -0.035 & -0.1356 & -0.43 & & -0.031 \\
\hline vdisroad & -0.0227 & -0.71 & & -0.004 & -0.0791 & -1.49 & & -0.009 & -0.0226 & -0.61 & & -0.005 \\
\hline vdevelop & 0.2326 & 2.15 & $* *$ & 0.043 & 0.2457 & 1.45 & & 0.029 & 0.3045 & 2.12 & ** & 0.070 \\
\hline vwassoc & 0.7503 & 1.88 & $*$ & 0.139 & -0.0896 & -0.16 & & -0.009 & 1.0449 & 2.09 & $* *$ & 0.242 \\
\hline givemeal & 0.3234 & 0.90 & & 0.055 & -0.2254 & -0.39 & & -0.033 & 1.3161 & 2.27 & $* *$ & 0.304 \\
\hline infra & 0.0179 & 0.56 & & 0.003 & 0.0668 & 1.14 & & 0.008 & -0.0125 & -0.30 & & -0.003 \\
\hline days6 & 0.0041 & 0.02 & & 0.005 & 0.3607 & 0.98 & & 0.047 & -0.0860 & -0.24 & & -0.020 \\
\hline tlivev & -0.0863 & -0.29 & & -0.016 & 0.3588 & 0.69 & & 0.042 & -0.2815 & -0.78 & & -0.065 \\
\hline pretrain & -0.0567 & -0.18 & & -0.012 & -0.4332 & -0.76 & & -0.053 & 0.2391 & 0.64 & & 0.055 \\
\hline tdaysnt & -0.0501 & -1.68 & $*$ & -0.009 & -0.0706 & -2.66 & $* *$ & -0.008 & -0.0257 & -0.67 & & -0.006 \\
\hline ptcoop & 0.3336 & 3.12 & $* *$ & 0.061 & 0.3625 & 2.21 & $* *$ & 0.041 & 0.2589 & 1.76 & * & 0.060 \\
\hline bwaterp & 0.6735 & 2.29 & ** & 0.122 & -0.0032 & -0.01 & & -0.003 & 1.3324 & 3.69 & ** & 0.308 \\
\hline ctratio & -0.0046 & -4.59 & $* *$ & -0.001 & -0.0041 & -2.96 & $* *$ & -0.001 & -0.0040 & -1.69 & $*$ & -0.001 \\
\hline male & 1.5391 & 7.38 & $* *$ & 0.285 & & & & & & & & \\
\hline cut 1 & 1.1334 & & & & 0.2870 & & & & 0.4737 & & & \\
\hline cut 2 & 2.1300 & & & & 1.2392 & & & & 1.6748 & & & \\
\hline $\log L$ & & -505.72 & & & & -221.14 & & & & -256.11 & & \\
\hline Restricted Log L & & -651.54 & & & & -289.59 & & & & -346.69 & & \\
\hline Pseudo R-square & & 0.2232 & & & & 0.2384 & & & & 0.2613 & & \\
\hline $\mathrm{N}$ & & 747 & & & & 394 & & & & 353 & & \\
\hline
\end{tabular}


Table 7

Different approaches to dealing with the CTRATIO variable

Dependent variable: current enrolment of girls aged 5-12 years old

\begin{tabular}{|c|c|c|c|c|c|c|}
\hline & & ogenous & & d form & VDISRO & instrument for \\
\hline & coefficient & t-value & coefficient & $t$-value & coefficient & t-value \\
\hline _cons & $\begin{array}{l}-0.6870 \\
\end{array}$ & -0.99 & -0.8769 & -1.33 & $\begin{array}{l}-0.0501 \\
\end{array}$ & -0.06 \\
\hline age5 & -2.1675 & $-5.26 * *$ & -2.2199 & $-5.47 * *$ & -2.1938 & $-5.36 * *$ \\
\hline age7 & 0.1267 & 0.31 & 0.1142 & 0.28 & 0.1092 & 0.27 \\
\hline age8 & -0.6441 & $-2.00 * *$ & -0.6815 & $-2.07 * *$ & -0.7019 & $-2.12 * *$ \\
\hline age9 & -0.1810 & -0.47 & -0.1847 & -0.49 & -0.1938 & -0.50 \\
\hline age10 & -0.7286 & $-2.23 * *$ & -0.7316 & $-2.24 * *$ & -0.8157 & $-2.41 * *$ \\
\hline age11 & -0.8717 & $-2.40 * *$ & -0.8958 & $-2.47 * *$ & -0.9460 & $-2.54 * *$ \\
\hline age 12 & -1.1847 & $-2.74 * *$ & -1.2031 & $-2.79 * *$ & -1.2250 & $-2.80 * *$ \\
\hline edu_mo & 0.1773 & $2.54 * *$ & 0.1887 & $2.66 * *$ & 0.1758 & $2.47 * *$ \\
\hline edu_fa & 0.1218 & $4.58 * *$ & 0.1171 & $4.22 * *$ & 0.1211 & $4.41 * *$ \\
\hline caslab & -0.3865 & -1.43 & -0.3954 & -1.48 & -0.4133 & -1.48 \\
\hline job & 0.0475 & 0.13 & 0.0567 & 0.15 & 0.0652 & 0.18 \\
\hline asset & 0.0353 & $3.26 * *$ & 0.0345 & $3.27 * *$ & 0.0350 & $3.40 * *$ \\
\hline pccrms & 0.0487 & 0.62 & 0.0512 & 0.63 & 0.0371 & 0.47 \\
\hline cowgoat & -0.0853 & $-2.11 * *$ & -0.0886 & $-2.11 * *$ & -0.0773 & $-2.09 * *$ \\
\hline landown & 0.0069 & 0.29 & 0.0058 & 0.23 & 0.0050 & 0.20 \\
\hline depend & -0.3294 & $-2.17 * *$ & -0.3313 & $-2.22 * *$ & -0.3185 & $-2.13 * *$ \\
\hline muslim & -0.2029 & -0.59 & -0.2452 & -0.69 & -0.2113 & -0.62 \\
\hline scst & -0.7135 & $-2.67 * *$ & -0.6981 & $-2.61 * *$ & -0.7381 & $-2.78 * *$ \\
\hline$o b c$ & -0.6657 & $-2.55 * *$ & -0.7182 & $-2.78 * *$ & -0.6760 & $-2.56 * *$ \\
\hline impgir & 1.9811 & $6.68 * *$ & 1.9945 & $6.80 * *$ & 1.8698 & $6.38 * *$ \\
\hline vvec & 0.1088 & 0.42 & 0.1161 & 0.45 & 0.1021 & 0.39 \\
\hline vdisroad & 0.0233 & 0.56 & 0.0205 & 0.50 & - & - \\
\hline vdevelop & 0.2989 & $2.96 * *$ & 0.3127 & $3.07 * *$ & 0.2701 & $2.51 * *$ \\
\hline vwassoc & 0.7244 & $1.73 *$ & 0.7294 & $1.77 *$ & 0.6797 & 1.62 \\
\hline givemeal & 1.0603 & $2.29 * *$ & 0.9790 & $2.14 * *$ & 1.1298 & $2.36 * *$ \\
\hline infra & -0.0640 & $-2.17 * *$ & -0.0515 & $-1.76 *$ & -0.0732 & $-2.29 * *$ \\
\hline days6 & 0.5950 & $2.23 * *$ & 0.6497 & $2.48 * *$ & 0.5543 & $2.24 * *$ \\
\hline tlivev & -0.1422 & -0.41 & -0.1542 & -0.45 & -0.1916 & -0.55 \\
\hline pretrain & 0.3626 & 1.00 & 0.2884 & 0.82 & 0.4024 & 1.05 \\
\hline tdaysnt & -0.0292 & -0.96 & -0.0277 & -0.94 & -0.0307 & -0.98 \\
\hline ptcoop & 0.0460 & 0.40 & 0.0409 & 0.36 & 0.0285 & 0.26 \\
\hline bwaterp & 0.9894 & $3.18 * *$ & 0.9246 & $2.99 * *$ & 1.0431 & $3.65 * *$ \\
\hline ctratio & -0.0029 & $-2.27 * *$ & & & -0.0070 & $-1.66 *$ \\
\hline $\log \mathrm{L}$ & & 0.82 & & 3.09 & & .25 \\
\hline Restricted Log L & & 9.55 & & .55 & & .55 \\
\hline Pseudo R-square & & 576 & & 541 & & 70 \\
\hline $\mathrm{N}$, mean dep var & & 0.7034 & & 0.7034 & & .7034 \\
\hline
\end{tabular}


Table 6

Mean values of variables: Himachal Pradesh vs full sample

\begin{tabular}{|c|c|c|c|}
\hline Variable & HP mean & Sample mean & "Shift effect"a \\
\hline AGE5 & 0.116 & 0.124 & +0.002 \\
\hline AGE7 & 0.164 & 0.161 & +0.000 \\
\hline AGE8 & 0.146 & 0.155 & +0.000 \\
\hline AGE9 & 0.131 & 0.113 & -0.000 \\
\hline AGE10 & 0.101 & 0.120 & +0.001 \\
\hline AGE11 & 0.097 & 0.092 & -0.000 \\
\hline AGE12 & 0.108 & 0.104 & -0.000 \\
\hline EDU_MO & 3.382 & 1.365 & +0.032 \\
\hline EDU_FA & 7.355 & 5.355 & +0.024 \\
\hline CASLAB & 0.082 & 0.158 & +0.003 \\
\hline $\mathrm{JOB}$ & 0.198 & 0.098 & +0.002 \\
\hline ASSET & 11.660 & 9.885 & +0.005 \\
\hline PCCRMS & 0.875 & 1.351 & -0.003 \\
\hline COWGOAT & 2.870 & 3.392 & +0.003 \\
\hline LANDOWN & 2.225 & 3.580 & -0.001 \\
\hline DEPEND & 1.229 & 1.436 & +0.005 \\
\hline MUSLIM & 0.041 & 0.097 & +0.001 \\
\hline SCST & 0.534 & 0.325 & -0.012 \\
\hline $\mathrm{OBC}$ & 0.116 & 0.298 & +0.010 \\
\hline IMPGIR & 0.970 & 0.90 & +0.010 \\
\hline VVEC & 0.340 & 0.531 & -0.005 \\
\hline VDISROAD & 2.437 & 3.329 & -0.001 \\
\hline VDEVELOP & 3.164 & 1.366 & +0.045 \\
\hline VWASSOC & 0.616 & 0.131 & +0.016 \\
\hline GIVEMEAL & 0.000 & 0.077 & -0.002 \\
\hline INFRA & 9.169 & 7.328 & -0.011 \\
\hline DAYS6 & 0.046 & 0.347 & -0.009 \\
\hline TLIVEV & 0.246 & 0.253 & +0.000 \\
\hline PRETRAIN & 0.769 & 0.674 & +0.004 \\
\hline TDAYSNT & 0.608 & 1.613 & +0.003 \\
\hline PTCOOP & 2.271 & 1.391 & +0.004 \\
\hline BWATERP & 0.671 & 0.361 & +0.020 \\
\hline CTRATIO & 44.182 & 71.152 & +0.004 \\
\hline MALE & 0.507 & 0.567 & -0.008 \\
\hline
\end{tabular}

a Difference between the HP mean and the sample mean, multiplied by the estimated "marginal effect" on current enrolment for boys and girls combined (see Table 4, first column).

Note: The means in this table are calculated using all children aged 5-12 as the reference group. 


\section{Appendix 1}

\section{The PROBE Survey ${ }^{39}$}

\section{Sample villages}

The villages covered by the PROBE survey are essentially a sub-sample of a random sample of villages studied in 1994 by the National Council of Applied Economic Research. ${ }^{40}$

For each of the states surveyed (Bihar, Madhya Pradesh, Rajasthan, Uttar Pradesh and Himachal Pradesh), villages were selected from the NCAER sample through stratified random sampling. The districts were grouped by level of female literacy, and sample districts were chosen at random from each group. Within the selected districts, villages were chosen at random among all NCAER villages in the 300-3,000 population range. ${ }^{41}$ Two to four villages were selected from each district, depending on the target number of districts in the relevant state. The target number of districts, in each case, was roughly proportional to the state population. ${ }^{42}$

A total of 122 villages were selected in this way. In each village, the investigators began with a detailed survey of all schools with a primary section (the 'sample schools'). Basic details of other education facilities (including non-formal education centres, adult literacy classes, etc.) were also recorded.

\section{Sample households}

For each sample village, a household listing was readily available from the earlier NCAER survey. In each village, 12 households were selected from that list through circular random sampling. A list of 'replacement households' was also drawn (also through random sampling). Whenever investigators were unable to find a household from the first list, they looked for a household from the second list. Since the main focus of the household survey was on primary schooling, households without any child in the 6-12 age group were skipped (in such cases, investigators moved to the closest neighbour).

39 This appendix is adapted from The PROBE Team (1999), pp. 143-145. We ignore the so-called 'neighbouring villages' discussed there, as they are irrelevant for our purposes (no households were surveyed in the 'neighbouring villages').

${ }^{40}$ The findings of the NCAER survey are reported in National Council of Applied Economic Research (1996a, 1996b). The NCAER's sampling procedure and related details are described in National Council of Applied Economic Research (1996a), chapters 1 and 2.

${ }^{41}$ Note that, in the original NCAER sample, villages are selected with probability proportional to size (using Lahiri's method); this avoids over-representation of small villages, both in the NCAER sample and in our own subsample.

${ }^{42}$ An exception to this rule was made for Himachal Pradesh, where a proportionately larger number of districts were surveyed (7 districts out of 12), given the special importance of this state in the PROBE project. In other words, Himachal Pradesh is somewhat over-represented in our sample. 
Though the household survey aimed at covering 12 households in each of the 122 sample villages, the actual sample size is smaller. This is partly because the investigators were unable to complete the full round of 12 households in some cases (they were instructed to give priority to the school survey), and partly because questionnaires deemed to be of insufficient quality were discarded at the data-verification stage. The data set used in this report has 1,143 households.

\section{Field work}

The PROBE survey took place between September 1996 and December 1996 (sequentially in different states). In each village, the survey began with an unannounced visit to the government primary school, followed by visits to other schools (government or private) with primary sections, as well as to other education facilities, if any. The 'village questionnaire' was then filled with the sarpanch (headman) or some other knowledgeable individual, followed by the household survey.

\section{Survey Questionnaires}

Three of the questionnaires used in the PROBE survey are used in this study.

Village questionnaire: This questionnaire involved the collection of basic data on village characteristics, e.g. accessibility, population size, social composition, availability of various facilities, and so on. The respondent was usually the sarpanch, or the head-teacher, or some other knowledgeable local resident.

School questionnaire: This questionnaire had two parts. The first part was filled with the headteacher (or, in his or her absence, the senior-most teacher among those present). The main focus, here as elsewhere, was on the primary section (classes 1 to 5). This part of the questionnaire dealt with matters such as infrastructural facilities, enrolment data, management problems, relations with parents, etc. The second part was addressed to the class-1 teacher (in his or her absence, teachers of successively higher classes were sought), and was concerned with his or her background, training, perceptions, work environment, teaching methods, etc.

Household questionnaire: This questionnaire had four parts, focusing respectively on (1) the household, (2) one selected 'currently-enrolled' child (see section 1.3 above), (3) one selected 'drop-out' child, and (4) one selected 'never-enrolled' child. Our study uses the first part only. The respondent was an adult, preferably the mother or father of children in the 6-12 age group.

Each questionnaire had space for both quantitative and qualitative data, as well for the investigators' personal observations. The PROBE report makes extensive use of these qualitative aspects of the survey, which have also guided much of our own work. 


\section{Appendix 2}

Marginal effects of the ordered logit model of schooling attainment in Table 5 (13-18 year olds)

\begin{tabular}{|c|c|c|c|c|c|c|c|c|c|}
\hline & $\begin{array}{c}\text { no } \\
\text { schooling }\end{array}$ & $\begin{array}{c}\text { All } \\
\text { dropout before } \\
\text { class } 5 \\
\end{array}$ & $\begin{array}{c}\text { complete } \\
\text { primary school }\end{array}$ & no schooling & $\begin{array}{c}\text { Boys } \\
\text { dropout before } \\
\text { class } 5 \\
\end{array}$ & $\begin{array}{c}\text { complete } \\
\text { primary school }\end{array}$ & no schooling & $\begin{array}{c}\text { Girls } \\
\text { dropout before } \\
\text { class } 5 \\
\end{array}$ & $\begin{array}{c}\text { complete } \\
\text { primary school }\end{array}$ \\
\hline AGE14 & -0.043 & -0.041 & 0.084 & -0.023 & -0.028 & 0.051 & -0.060 & -0.051 & 0.112 \\
\hline AGE15 & -0.007 & -0.007 & 0.014 & 0.019 & 0.023 & -0.042 & -0.038 & -0.033 & 0.071 \\
\hline AGE16 & -0.024 & -0.023 & 0.047 & -0.018 & -0.021 & 0.039 & 0.018 & 0.016 & -0.034 \\
\hline AGE17 & -0.008 & -0.008 & 0.016 & 0.004 & 0.005 & -0.010 & -0.034 & -0.029 & 0.062 \\
\hline EDU_MO & -0.035 & -0.034 & 0.069 & -0.020 & -0.024 & 0.045 & -0.047 & -0.040 & 0.086 \\
\hline EDU_FA & -0.010 & -0.009 & 0.019 & -0.006 & -0.007 & 0.013 & -0.015 & -0.013 & 0.028 \\
\hline CASLAB & -0.001 & -0.001 & 0.003 & 0.017 & 0.020 & -0.036 & -0.052 & -0.044 & 0.096 \\
\hline JOB & -0.010 & -0.009 & 0.019 & 0.019 & 0.023 & -0.041 & -0.018 & -0.016 & 0.034 \\
\hline ASSET & -0.001 & -0.001 & 0.002 & 0.000 & 0.000 & 0.000 & -0.002 & -0.002 & 0.004 \\
\hline PCCRMS & -0.003 & -0.003 & 0.006 & -0.018 & -0.021 & 0.039 & 0.007 & 0.006 & -0.012 \\
\hline COWGOAT & -0.006 & -0.006 & 0.012 & -0.010 & -0.012 & 0.023 & 0.001 & 0.001 & -0.002 \\
\hline LANDOWN & 0.002 & 0.002 & -0.005 & 0.002 & 0.003 & -0.005 & 0.002 & 0.002 & -0.004 \\
\hline DEPEND & 0.017 & 0.017 & -0.034 & -0.002 & -0.003 & 0.005 & 0.053 & 0.045 & -0.098 \\
\hline MUSLIM & 0.031 & 0.029 & -0.060 & 0.031 & 0.037 & -0.067 & 0.048 & 0.041 & -0.089 \\
\hline SCST & 0.043 & 0.041 & -0.083 & 0.022 & 0.027 & -0.049 & 0.060 & 0.051 & -0.111 \\
\hline OBC & -0.012 & -0.011 & 0.023 & -0.018 & -0.022 & 0.040 & 0.019 & 0.016 & -0.035 \\
\hline IMPGIRL & -0.089 & -0.085 & 0.175 & -0.059 & -0.070 & 0.129 & -0.083 & -0.070 & 0.153 \\
\hline VVEC & 0.022 & 0.021 & -0.042 & 0.016 & 0.019 & -0.035 & 0.017 & 0.014 & -0.031 \\
\hline VDISROAD & 0.002 & 0.002 & -0.004 & 0.004 & 0.005 & -0.009 & 0.003 & 0.002 & -0.005 \\
\hline VDEVELOP & -0.022 & -0.021 & 0.043 & -0.013 & -0.016 & 0.029 & -0.038 & -0.032 & 0.070 \\
\hline VWASSOC & -0.071 & -0.068 & 0.139 & 0.004 & 0.005 & -0.009 & -0.130 & -0.111 & 0.242 \\
\hline GIVEMEAL & -0.028 & -0.027 & 0.055 & 0.015 & 0.018 & -0.033 & -0.164 & -0.140 & 0.304 \\
\hline INFRA & -0.002 & -0.002 & 0.003 & -0.004 & -0.004 & 0.008 & 0.002 & 0.001 & -0.003 \\
\hline DAYS6 & -0.002 & -0.002 & 0.005 & -0.022 & -0.026 & 0.047 & 0.011 & 0.009 & -0.020 \\
\hline TLIVEV & 0.008 & 0.008 & -0.016 & -0.019 & -0.023 & 0.042 & 0.035 & 0.030 & -0.065 \\
\hline PRETRAIN & 0.006 & 0.006 & -0.012 & 0.024 & 0.029 & -0.053 & -0.030 & -0.026 & 0.055 \\
\hline TDAYSNT & 0.005 & 0.005 & -0.009 & 0.004 & 0.004 & -0.008 & 0.003 & 0.003 & -0.006 \\
\hline РTCOOP & -0.031 & -0.030 & 0.061 & -0.019 & -0.022 & 0.041 & -0.032 & -0.028 & 0.060 \\
\hline CTRATIO & 0.000 & 0.000 & -0.001 & 0.000 & 0.000 & -0.001 & 0.001 & 0.000 & -0.001 \\
\hline BWATERP & -0.063 & -0.060 & 0.122 & 0.001 & 0.002 & -0.003 & -0.166 & -0.142 & 0.308 \\
\hline MALE & -0.146 & -0.139 & 0.285 & & & & & & \\
\hline
\end{tabular}


